\title{
Probabilistic Earthquake Hazard in Metropolitan Taipei and Its Surrounding Regions
}

\author{
Chin-Tung Cheng ${ }^{1}$, Chyi-Tyi Lee ${ }^{2, *}$, Po-Shen Lin ${ }^{3}$, Bor-Shiun Lin ${ }^{1}$, Yi-Ben Tsai ${ }^{4}$, and Syi-Jang Chiou ${ }^{5}$ \\ ${ }^{1}$ Sinotech Engineerning Consultants, Inc., Taipei, Taiwan, ROC \\ ${ }^{2}$ Institute of Applied Geology, National Central University, Jhongli, Taiwan, ROC \\ ${ }^{3}$ Institute of Geophysics, National Central University, Jhongli, Taiwan, ROC \\ ${ }^{4}$ Pacific Gas and Electric Company, San Francisco, CA., USA \\ ${ }^{5}$ California Department of Transportation, Sacramento, CA., USA
}

Received 29 April 2008, accepted 11 November 2009

\begin{abstract}
The aim of this study is to evaluate the probability of seismic hazard for the Taipei metropolitan area in northern Taiwan from readily available information, including the attenuation relationship of peak ground acceleration (PGA), tectonic settings, fault-slip data, and seismicity. The PGA seismic hazard mapping reveals that the hazard level in this area increases going from northwest to southeast and southwest. There are four important earthquake sources that contribute to the hazard level: (1) the plate-boundary interface (subduction zone interface) located offshore of the Ilan plain; (2) the intraslab subduction zone underneath Taipei itself; (3) the crustal areal sources in eastern Taiwan and central Taiwan; and (4) the nearby active Shanchiao fault. The slip-rate of the targeted fault is relatively low, and therefore not the most dangerous earthquake source revealed in the 475-year return period. However, there is no doubt that the target fault is the control source in the 2475 -year return period. Furthermore, higher PGAs are predicted using the attenuation relationship of subduction zone earthquake sources rather than crustal earthquake sources, meaning an increase of the seismic hazard level over previous estimates. Consequently, more attention needs to be paid to subduction zone sources when considering mitigation of seismic hazards in northern Taiwan.
\end{abstract}

Key words: Taipei Basin, Seismic hazard, Subduction zone earthquakes, Shanchiao fault

Citation: Cheng, C. T., C. T. Lee, P. S. Lin, B. S. Lin, Y. B. Tsai, and S. J. Chiou, 2010: Probabilistic earthquake hazard in metropolitan Taipei and its surrounding regions. Terr. Atmos. Ocean. Sci., 21, 429-446, doi: 10.3319/TAO.2009.11.11.01(TH)

\section{INTRODUCTION}

The Taipei metropolitan area is the political, economic, and cultural center of Taiwan. However, the area is located in a Quaternary sediment-filled basin, situated on the subduction zone where the Philippine Sea plate is being forced underneath the Eurasian plate. There is high seismicity in several seismogenic zones surrounding metropolitan Taipei. The utmost attention should be paid to evaluating the seismic threat level for hazard mitigation in this heavily populated area. This study utilizes readily available information including the attenuation relationship of peak ground acceleration (PGA), tectonic settings, fault-slip data, and seismicity data to evaluate the probabilistic seismic hazard level at different locations in northern Taiwan.

\footnotetext{
* Corresponding author

E-mail:ct@ncu.edu.tw
}

Probabilistic seismic hazard analysis (PSHA) is defined as evaluation of the probability or likelihood that there will be ground motion in excess of certain levels during a specific time period. The basic analytical procedure used in present-day PSHA was originally proposed by Cornell (1968). Since that time there has been significant progress in scientific understanding of the earthquake process and in the technique for evaluation of the relevant seismology, geological, and geophysical data. PSHA provides greater flexibility in predicting the distribution of future earthquakes in terms of time, space, and size, and the resultant level of ground motion at a specific site. The treatment of the uncertainty in defining the parameters of PSHA has become a standard-practice (NRC 1988; Coppersmith 1991). This also is considered in the present study.

PSHA studies carried out before the occurrence of the Chi-Chi earthquake in Taiwan on 21 September 1999 (Ma 
et al. 1999; Kao and Chen 2000) completely underestimated the level of earthquake hazard in central Taiwan. Previous PSHA techniques suffered from drawbacks due to uncertainty of the input information and deficiencies in the analytical process (Lee et al. 2002). After the Chi-Chi earthquake, it was found that the highest ground motion and region of most significant damage were located on the hanging wall of the Chelungpu fault rupture (Tsai and Huang 2000). Observations from the Chi-Chi earthquake experiences have helped to recognize the characteristics of the geometry and activity of active faults in Taiwan which should be helpful for seismic hazard analysis. In addition, adopting the proper attenuation law for strong ground-motion in the near fields is also very important.

In previous work (before the Chi-Chi earthquake), it was found that the hazard levels were higher in the Hualien and the Chiayi-Tainan regions, regardless of methods or assumptions adopted. These unreasonable results arose because recent research on local crustal faults and subduction zones was not taken into account, which distorted the direction and meanings of PSHA (Cheng et al. 2007).

Using state-of-the-art PSHA methodologies (NRC 1988; EERI 1989; Coppersmith 1991; Campbell et al. 2002; Cheng et al. 2007) we determine the areas in the Taipei metropolitan area with the most significant seismic hazards. The analysis is based on inputs with emphasis on various seismic sources. Uncertainty in the PSHA process is handled with the logic tree method. The earthquake scenarios for loss estimation are indicated by deaggregation of the PSHA results. Finally, a brief discussion of the significance of identifying earthquake sources in the Taipei area and of adopting the proper strong motion attenuation model for PSHA is given.

\section{REGIONAL TECTONIC SETTING}

Taiwan is situated on the boundary between the Eurasian plate (EP) and the Philippine Sea plate (PSP), an area where active oblique collision and subduction take place (Big 1972; Wu 1978; Tsai 1986) (Fig. 1). The arc-continent collision, which started in the Late Miocene created the highly deformed terrain of Taiwan. The resulting compression stresses have caused intense folding and thrusting of the Central Mountain Range. Due to the oblique nature of the collision, the folding and thrusting process started earlier in northern Taiwan and gradually propagated southward. Present-day active crustal deformations are still vigorously taking place in central and southern Taiwan. In contrast, the tectonic setting in northern Taiwan is different from that in the main collision zone (Lee and Wang 1988). An extensional stress regime, normal faulting mechanism, and eruption of island-arc type volcanic lava have occurred in northern Taiwan (Lee and Wang 1988; Teng and Lee 1996). These features are interpreted as being closely related to the northward subduction of the PSP underneath the EP that is occurring in northeastern Taiwan and the subsequent opening of the Okinawa Trough.

\section{SEISMICITY AND DISASTROUS EARTHQUAKES}

A review of the historical seismicity is carried out using the catalog of pre-instrumental earthquakes compiled by Cheng and Yeh (1989). This catalog provides a list of historical earthquakes dating back as far as 1604. According to this catalog, several significant historical earthquakes are thought to have occurred in Taipei and the surrounding regions. The disastrous earthquakes in the last four centuries, where the epicenters are known through historical documents or instrumental observations, are shown in Fig. 1. A large earthquake with an estimated magnitude of 7 occurred in 1694. It caused large subsidence (less than 5 meters, with no available epicenter location) in the northwestern part of the Taipei Basin (Wang et al. 1994; Chan et al. 2007). During the $19^{\text {th }}$ century, there were several earthquakes that caused considerable damage in the Taipei area. These destructive earthquakes included earthquakes in 1815 (M 6.5), 1853, 1860, 1865 (M 6.0), 1867 (M 7.0), 1881 (M 6.2), and 1893 (Hsu 1983; Tsai 1985; Cheng and Yeh 1989). The 1815 earthquake, which was located in present-day Shihdin, in the eastern corner of the Taipei Basin, was a relatively deep earthquake, which caused damage in Taipei City. The famous and delicate Longshan Temple totally collapsed during this earthquake. The 1867 earthquake, which occurred offshore of Keelung in northern Taiwan, caused a series of tsunamis and several hundred people drowned. In April 15 of 1909, an 80-km deep, M 7.3 earthquake occurred in the Taipei Basin with its epicenter at Chunghe. This earthquake caused 9 deaths, 51 people injured, 122 buildings collapsed and 1050 buildings damaged.

Recent instrumental observations of seismicity in northern Taiwan have been used to help compile another earthquake catalog (Tsai and Chen 1999). This catalog contains observed earthquakes since 1900 and uses the moment magnitude $\left(\mathrm{M}_{\mathrm{W}}\right)$ as the magnitude scale. The information sources for this catalog are the Central Weather Bureau Seismic Network, operated by the Central Weather Bureau, and the Taiwan Telemetry Seismic Network, operated by the Institute of the Earth Sciences, Academia Sinica. There are several other earthquake catalogs for Taiwan, but these use either the local magnitude $\left(\mathrm{M}_{\mathrm{L}}\right)(\mathrm{Cheng}$ and Yeh 1989) or surface-wave magnitude $\left(\mathrm{M}_{\mathrm{S}}\right)$. The moment magnitude $\mathrm{M}_{\mathrm{W}}$ is the preferred magnitude for our seismic hazard analysis, because $\mathrm{M}_{\mathrm{W}}$ is more predominant than other magnitudes and fits well with the physical phenomena and models. $\mathrm{Wu}$ et al. (2001) have derived a relationship that can be used to convert Taiwan $\mathrm{M}_{\mathrm{L}}$ to $\mathrm{M}_{\mathrm{W}}$ which has been adapted for catalog compilation to maintain magnitude uniformity and completeness. 
Prior to PSHA, the standard procedures were performed to remove dependent earthquakes (foreshocks and aftershocks) and intended to create mainshock catalogs (Youngs et al. 1987). The resulting catalogs of independent earthquakes of Taiwan were adopted from Cheng (2002). The spatial distributions of the independent shallow crustal earthquakes (with a focal depth equal to or less than $35 \mathrm{~km}$ ) and relative deep earthquakes (with a focal depth larger than $35 \mathrm{~km}$ ) are shown in Figs. 2 and 3, respectively. The shallow crustal earthquake activity during the past 100 years in the Taipei area is sparse (Fig. 2) and is poorly correlated with known active faults. The cluster of earthquakes north of Taipei is probably related to the volcanic activity of the Tatun volcanic group.

Intermediate-depth and deep earthquakes (with a focal depth greater than $35 \mathrm{~km}$ ) occur mostly in northeastern Taiwan (Fig. 3) where an earthquake occurrence is closely related to the north-dipping subduction zone of the PSP moving under the EP along the Ryukyu Trench. There are three large earthquakes that should be noted in seismic hazard analysis for northern Taiwan (Cheng and Yeh 1989). The first is the 1909/04/15 Taipei earthquake $\left(\mathrm{M}_{\mathrm{L}} 7.3\right.$, with

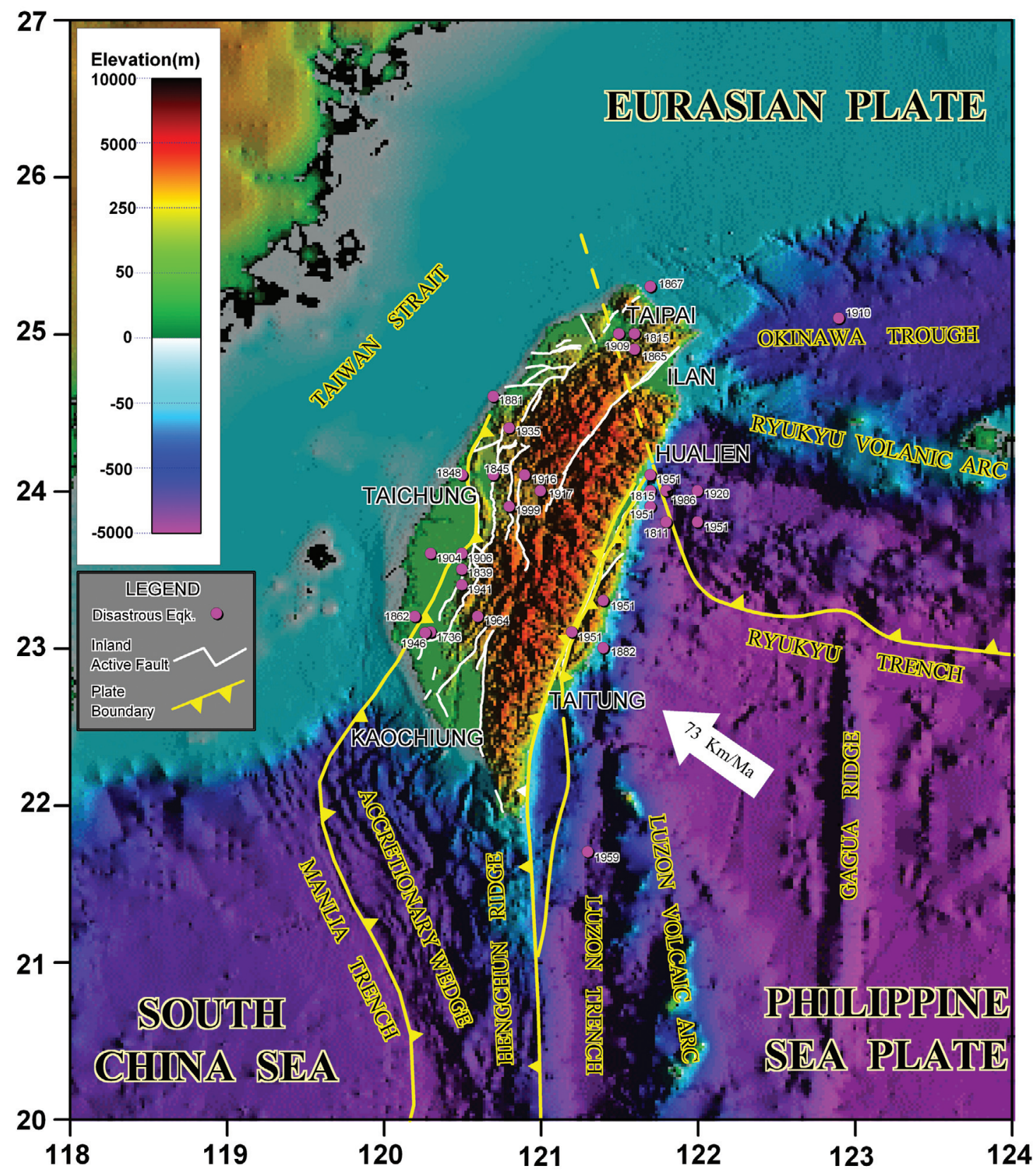

Fig. 1. Seismotectonic framework of Taiwan and its surrounding regions. Thick yellow lines represent plate boundaries. Thin white lines indicate the inland active faults. The purple solid circles represent the epicenter of the destructive earthquakes, which an epicenter is available. Philippine Sea plate is moving toward the island of Taiwan at a velocity of $73 \mathrm{~km} \mathrm{Ma}^{-1}$, and the moving direction is shown as arrow sign. 


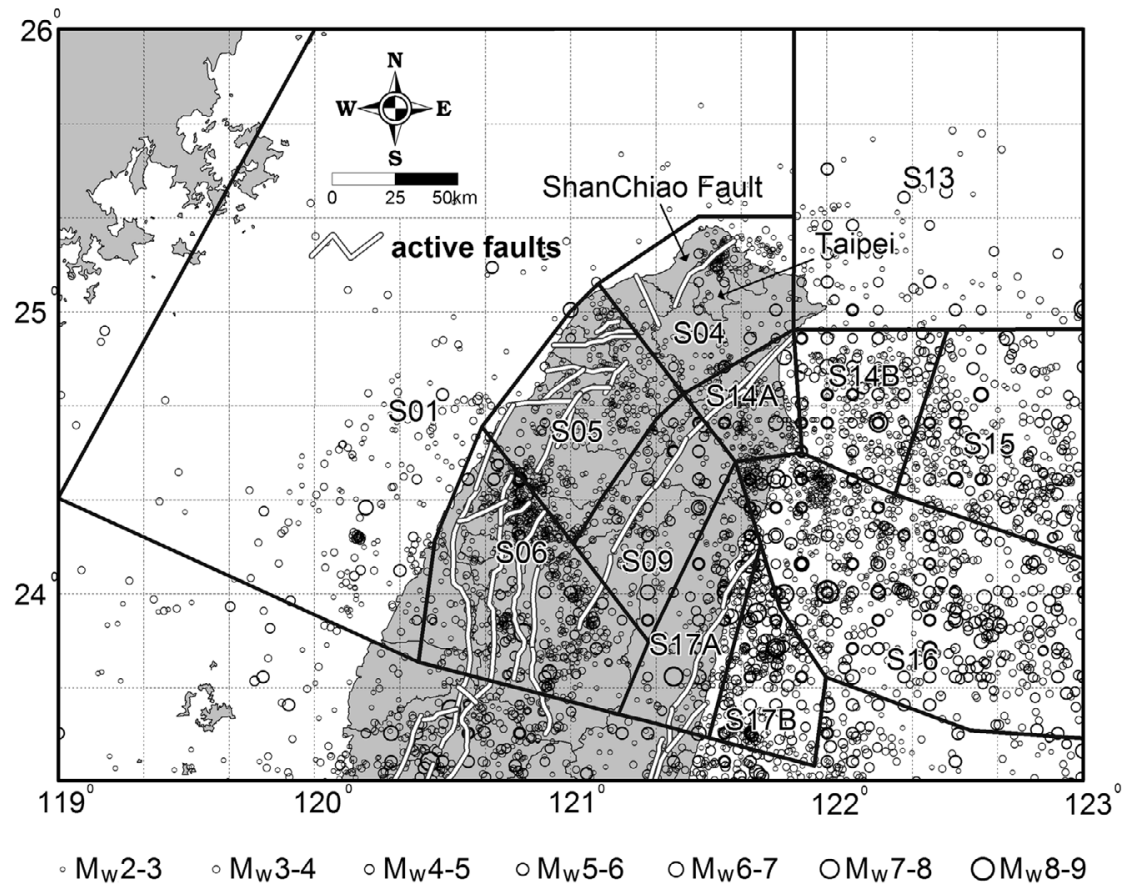

Fig. 2. Locations of crustal areal earthquake sources and active faults included in PSHA of this study. Independent shallow crustal earthquakes (depth $<35 \mathrm{~km}$ ) which occurred from 1900 through 1999 are shown.

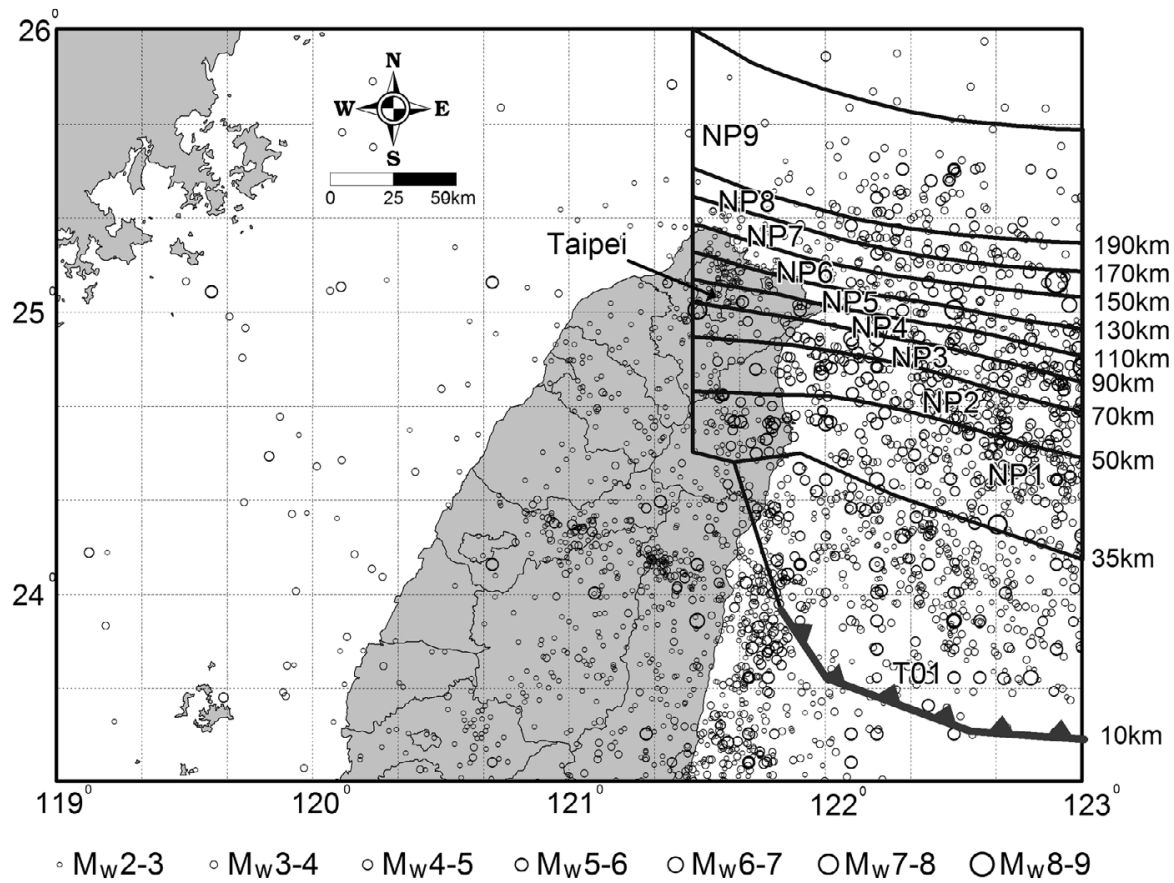

Fig. 3. Isobaths contours of the top of subducting Philippine Sea plate and spatial distribution of independent intermediate-depth and deep earthquakes (depth $\geqq 35 \mathrm{~km}$ ) in northern Taiwan. Locations of subduction zone earthquake sources (intraslab NP1 NP9, interface T01) for PSHA of this study are also shown.

a focal depth of $80 \mathrm{~km})$. The second, which took place on $1910 / 4 / 12$, was also a deep earthquake $\left(\mathrm{M}_{\mathrm{L}} 8.1\right.$, with a focal depth of $200 \mathrm{~km})$. The third one, which took place on $1920 / 6 / 23$, was a shallow earthquake $\left(\mathrm{M}_{\mathrm{L}} 8.1\right.$, with a fo- cal depth of less than $35 \mathrm{~km}$ ), occurring at the interface of north-dipping subduction zone and offshore of the Ilan plain. All of these caused widespread damage in northern Taiwan. 


\section{EARTHQUAKE SOURCES AND RECURRENCE RATE}

Based on our understanding of the tectonic setting of Taiwan, four groups of seismic sources are identified and considered for evaluating earthquake hazards in the Taipei area. The first group includes nearby crustal faults. The second source group includes a set of crustal areal sources. Details on each source, which represents the distributed crustal seismicity in northern and northeastern Taiwan, can be referred to in Cheng (2002). The third group includes the intermediate depth and deep earthquakes that occurred within the subducting PSP. The fourth group is related to the interface between the Eurasian plate and the north-dipping PSP. Further information and earthquake recurrence rate for these four earthquake sources are given below. The locations of the faults are shown in Fig. 2.

Previous earthquake recurrence rate estimations have been based primarily on historic seismicity or a generalized faulting model in which faults have been randomly distributed within seismotectonic provinces (Tsai et al. 1987; Loh et al. 1991). The truncated-exponential model has usually been employed when estimating the earthquake recurrence rate for Taiwan from the earthquake catalogs of the last century. However, it is unreasonable to use this model to extrapolate the recurrence rate of a large earthquake from the distribution trend of small to medium magnitude earthquakes simply because the recurrence interval of large earthquakes induced by a specific active fault can cover hundreds or thousands of years. The adoption of a fault slip rate to develop a characteristic-earthquake model is more appropriate for estimating the recurrence interval of large earthquakes along an active fault. According to results of recent PSHA research, the truncated-exponential model is appropriate for calculating the recurrence rate of areal source or random faults (Schwartz and Coppersmith 1984; Davison and Scholz 1985; Coppersmith 1991; Wesnousky 1994; Cheng et al 2007).

The most important factor for calculating the recurrence rate for active faults is the slip rate (Youngs and Coppersmith 1985; Hu et al. 2001). The United States Geological Survey (USGS) continually updates fault slip data and revises National Seismic Hazard Maps (Frankel et al. 2002; Petersen et al. 2008). Lee (1999), Campbell et al. (2002), Cheng (2002), and Cheng et al. (2007) also used the slip rates of active faults to evaluate the seismic hazard for risk management in Taiwan. They confirmed that the slip rate of active faults indeed dominates the results of PSHA and hazard distribution on seismic hazard maps.

\subsection{Nearby Crustal Faults}

Forty-nine faults have been reexamined and slip rates estimated in the land area of Taiwan (Lee 1999; Cheng
2002). Some of those are identified from damage locations recorded in historical documents. Others are indicated by either cutting through Holocene-Late Pleistocene deposits or expressing significant geomorphic features of recent movement (Lee 1999). The location of each fault trace was reexamined on multi-source images, and then digitized to produce geographic information system (GIS) maps. There are 28 active faults identified within $150 \mathrm{~km}$ of Taipei, as shown in Fig. 2 and Table 1. Six of these, located in the Western Foothills (No. 01+02+03, 14BT, 15, 16, 17, 18) and three in the Eastern Longitudinal Valley (No. 42, 43, 44), have ruptured and caused damage in the past four centuries (Lee 1999). The length, attitude, displacement, slip rate, and magnitude of Taiwan's active faults have been estimated by Lee (1999) and the recurrence interval of each fault calculated based on the slip rate (Cheng 2002). A summary of the active fault information used in this study is shown in Table 1. The order of magnitude-range of slip rates begins with less than or equal to $0.4 \mathrm{~mm} \mathrm{yr}^{-1}$ and ends with greater than or equal to $20 \mathrm{~mm} \mathrm{yr}^{-1}$. Estimation of a specific fault slip rate is usually obtained from geological maps, fault trench results, and GPS velocity around faults, as in Yu et al. (1997) and Yu and Chen (1998). The maximum magnitude of the largest earthquake among these active faults can be estimated using the empirical relations of fault length versus magnitude or fault rupture area versus magnitude (Wells and Coppersmith 1994). Hence, the recurrence of earthquakes at crustal faults is typically modeled by the characteristic magnitude model using slip rate and maximum magnitude (Youngs and Coppersmith 1985).

The closest active fault to Taipei is fault No. $01+02$ +03, which represents the combined Huangchi fault (No. 1), Hsiaoyukeng fault (No. 2), and Shanchiao fault (No. 3), as discussed by Lee (1999) and Cheng et al. (2007). Seismic reflection profiling across the Shanchiao fault (Wang and Sun 1999) reveals a clear offset of Holocene deposits (the Shungshan formation) and suggests recent activity on this fault. The 1694 earthquake, which caused large subsidence of the western portion of the Taipei Basin, is probably associated with this fault (Huang et al. 2007). Based on the displacement of a reference horizon and the age of the horizon, Lee (1999) estimated the slip rate to be about $2 \mathrm{~mm} \mathrm{yr}^{-1}$. According to the characteristic-earthquake model, the characteristic earthquake along fault No. $01+02+03$ would be approximately $\mathrm{M}_{\mathrm{W}} 7.0$ with a recurrence interval of around 543 yr (Cheng 2002).

\subsection{Crustal Areal Sources}

Recent crustal seismicity in northern Taiwan has been divided into twelve individual crustal areal sources (Fig. 2). The parameters of the truncated-exponential model are shown in Table 2a. The source areas were defined in accor- 
Table 1. Characterization of fault sources adopted in PSHA of this study. The information of these active faults is referred to Lee (1999) and Cheng (2002) and the deviation of slip rate and characteristic maximum earthquake magnitude $\left(m_{u}\right)$ of each fault was estimated for addressing the uncertainties in logic tree. We assigned a weight $(0.6)$ to present probability of occurrence to mean value, and lower weight $(0.2)$ to mean \pm deviation in logic tree.

\begin{tabular}{|c|c|c|c|c|c|c|c|c|c|c|c|c|c|}
\hline \multirow[b]{2}{*}{ 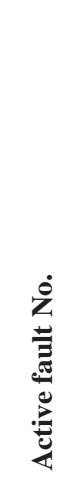 } & \multirow[b]{2}{*}{ 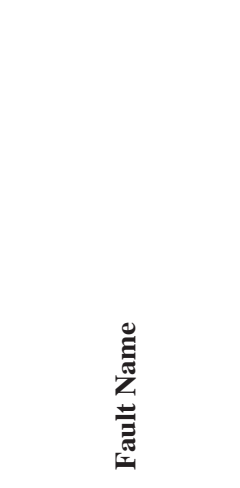 } & \multirow[b]{2}{*}{  } & \multirow[b]{2}{*}{ 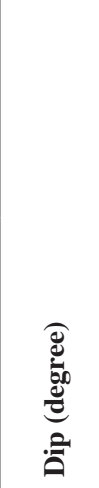 } & \multirow[b]{2}{*}{ 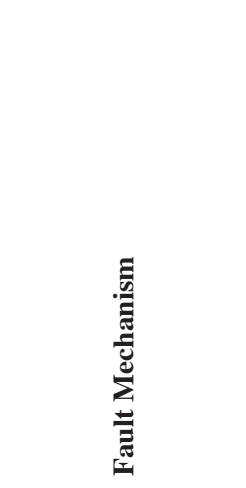 } & \multirow[b]{2}{*}{ 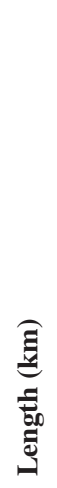 } & \multicolumn{2}{|c|}{ 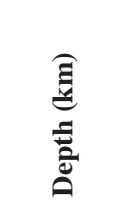 } & \multirow[b]{2}{*}{ 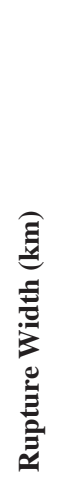 } & \multirow[b]{2}{*}{ 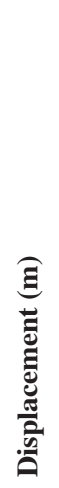 } & \multirow[b]{2}{*}{  } & \multirow[b]{2}{*}{ 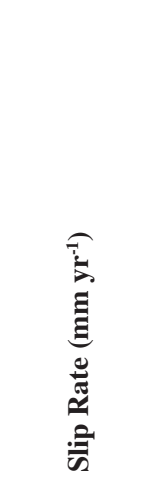 } & \multirow{2}{*}{ 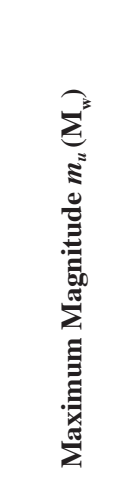 } & \multirow{2}{*}{ 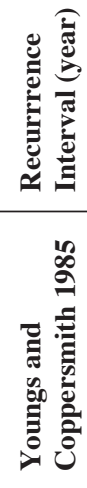 } \\
\hline & & & & & & $\stackrel{0}{\theta}$ & $\underbrace{0}_{0}$ & & & & & & \\
\hline $\begin{array}{l}1+ \\
2+ \\
3\end{array}$ & $\begin{array}{l}\text { Huangchi+ } \\
\text { Hsiaoyukeng+ } \\
\text { Shanchiao }\end{array}$ & NNE & 60SE & Normal \& Sinistral & 36 & 0 & 15 & 17 & 1.8 & 624 & $2.0 \pm 1.0$ & $7.0 \pm 0.2$ & 543 \\
\hline 4 & Nankan & NNW & $80 \mathrm{NW}$ & Normal \& Dextral & 22 & 0 & 10 & 10 & 0.7 & 223 & $0.4 \pm 0.2$ & $6.5 \pm 0.2$ & 1352 \\
\hline 5 & Shuanglienpo & ENE & 50SE & Reverse & 12 & 2 & 10 & 10 & 0.4 & 125 & $0.5 \pm 0.25$ & $6.2 \pm 0.2$ & 567 \\
\hline 6 & Yangmei & ENE & $50 \mathrm{NW}$ & Reverse & 20 & 2 & 10 & 10 & 0.8 & 261 & $0.5 \pm 0.25$ & $6.6 \pm 0.2$ & 1082 \\
\hline 7 & Hukou & ENE & $45 \mathrm{SE}$ & Thrust & 32 & 0 & 12 & 17 & 1.5 & 543 & $1.0 \pm 0.5$ & $6.9 \pm 0.2$ & 733 \\
\hline 8 & Hsinchu & E-W & $45 \mathrm{~S}$ & Thrust & 28 & 0 & 12 & 17 & 1.4 & 475 & $1.5 \pm 0.75$ & $6.8 \pm 0.2$ & 395 \\
\hline 9 & Tapingti & NNE & 45SE & Thrust & 15 & 0 & 12 & 17 & 0.8 & 255 & $0.6 \pm 0.3$ & $6.5 \pm 0.2$ & 653 \\
\hline 10 & Chutung & NE & 50SE & Reverse & 14 & 0 & 12 & 16 & 0.7 & 219 & $0.6 \pm 0.3$ & $6.5 \pm 0.2$ & 760 \\
\hline 11 & Hsincheng & $\mathrm{N} 40 \mathrm{E}$ & $45 \mathrm{SE}$ & Thrust & 22 & 0 & 12 & 17 & 1.1 & 373 & $2.0 \pm 1.0$ & $6.7 \pm 0.2$ & 267 \\
\hline 12 & Touhuanping & E-W & $80 \mathrm{~S}$ & Dextral & 27 & 0 & 12 & 12 & 1.0 & 329 & $2.5 \pm 1.25$ & $6.7 \pm 0.2$ & 242 \\
\hline 13 & Seztan & N10E & $75 \mathrm{~W}$ & Reverse & 35 & 0 & 12 & 12 & 1.3 & 435 & $2.5 \pm 1.25$ & $6.8 \pm 0.2$ & 259 \\
\hline 14 & Shinchonshan & N10E & $60 \mathrm{E}$ & Reverse & 16 & 0 & 12 & 14 & 0.7 & 222 & $2.5 \pm 1.25$ & $6.5 \pm 0.2$ & 180 \\
\hline $14 \mathrm{BT}$ & Miaoli blind thrust & N10E & $30 \mathrm{E}$ & Reverse \& Dextral & 37 & 2 & 15 & 26 & 2.6 & 962 & $5.0 \pm 2.5$ & $7.2 \pm 0.2$ & 223 \\
\hline 15 & Tuntzechiao & N60E & 90 & Dextral & 20 & 0 & 15 & 15 & 0.9 & 300 & $2.5 \pm 1.25$ & $6.6 \pm 0.2$ & 226 \\
\hline 16 & Sanyi & NNE & $40 \mathrm{E}$ & Thrust & 22 & 0 & 15 & 23 & 1.5 & 513 & $1.0 \pm 0.15$ & $6.9 \pm 0.2$ & 940 \\
\hline 17 & Chelungpu & $\mathrm{N}-\mathrm{S}$ & $40 \mathrm{E}$ & Thrust & 90 & 0 & 20 & 31 & 6.8 & 2800 & $15.0 \pm 7.5$ & $7.7 \pm 0.2$ & 182 \\
\hline 18 & Changhua & NNS & $30 \mathrm{E}$ & Thrust & 85 & 2 & 15 & 28 & 5.4 & 2354 & $15.0 \pm 7.5$ & $7.6 \pm 0.2$ & 153 \\
\hline 39 & Ilan & $\mathrm{NE}$ & $60 \mathrm{SE}$ & Normal & 30 & 0 & 15 & 17 & 1.5 & 520 & $1.5 \pm 0.75$ & $6.9 \pm 0.2$ & 623 \\
\hline 40 & Chiaochi & NE & $60 \mathrm{SE}$ & Normal & 25 & 0 & 15 & 17 & 1.3 & 433 & $2.0 \pm 1.0$ & $6.8 \pm 0.2$ & 397 \\
\hline $41 \mathrm{a}$ & Lishan (a) & NNE & $60 \mathrm{E}$ & Normal & 30 & 0 & 15 & 17 & 1.5 & 520 & $1.5 \pm 0.75$ & $6.9 \pm 0.2$ & 623 \\
\hline $41 b$ & Lishan (b) & NNE & $60 \mathrm{E}$ & Normal & 25 & 0 & 15 & 17 & 1.3 & 433 & $1.2 \pm 0.6$ & $6.8 \pm 0.2$ & 666 \\
\hline $41 \mathrm{c}$ & Lishan (c) & NNE & $60 \mathrm{E}$ & Normal & 30 & 0 & 15 & 17 & 1.5 & 520 & $1.0 \pm 0.5$ & $6.9 \pm 0.2$ & 940 \\
\hline $41 \mathrm{~d}$ & Lishan (d) & NNE & $60 \mathrm{E}$ & Normal & 30 & 0 & 15 & 17 & 1.5 & 520 & $1.0 \pm 0.5$ & $6.9 \pm 0.2$ & 940 \\
\hline 42 & Meilun & N30E & $50 \mathrm{E}$ & Reverse \& Sinistral & 30 & 0 & 30 & 39 & 3.1 & 1175 & $20.0 \pm 10.0$ & $7.3 \pm 0.2$ & 83 \\
\hline 43 & Ueimei & N30E & $50 \mathrm{E}$ & Reverse \& Sinistral & 45 & 0 & 30 & 39 & 4.5 & 1762 & $20.0 \pm 10.0$ & $7.5 \pm 0.2$ & 111 \\
\hline 44 & Yuli & N30E & $50 \mathrm{E}$ & Reverse \& Sinistral & 48 & 0 & 30 & 39 & 4.7 & 1880 & $16.0 \pm 8.0$ & $7.5 \pm 0.2$ & 130 \\
\hline
\end{tabular}


Table 2. Characterization of (a) a crustal areal source, (b) subduction intraslab source, and (c) subduction interface source, in northern Taiwan. For earthquake recurrence estimation, the parameters in (a) and (b) are adopted for truncated-exponential model and (c) is adopted for characteristicearthquake model. The standard deviation of earthquake cumulative rate $\dot{N}\left(\mathrm{~m}_{o}\right)$ and $b$ value in (a) and (b) are shown in parentheses, their mean value are assigned weight $(0.63)$ to present probability of occurrence and mean \pm standard deviation are assigned lower weight $(0.185)$ in logic tree. The uncertainties of slip rate, dip angle, and $m_{u}$ were also presented and the relative weights of them are shown in the parentheses.

(a) Characterization of crustal areal sources

\begin{tabular}{|c|c|c|c|c|c|c|c|}
\hline Source code & $m_{o}^{*}$ & $\dot{N}\left(m_{o}\right)\left[ \pm \sigma_{\dot{N}\left(m_{o}\right)}\right]^{* *}$ & $b\left( \pm \sigma_{b}\right)^{* *}$ & \multicolumn{3}{|c|}{$\boldsymbol{m}_{u}{ }^{* * *}$} & Largest recorded $M_{W}$ \\
\hline S01 & 3.5 & $1.343( \pm 0.218)$ & $0.849( \pm 0.118)$ & $6.5(0.2)$ & $6.6(0.6)$ & $6.7(0.2)$ & 6.2 \\
\hline S04 & 2.5 & $3.796( \pm 0.532)$ & $0.800( \pm 0.084)$ & $6.4(1.0)$ & & & 5.6 \\
\hline S05 & 2.5 & $7.038( \pm 0.507)$ & $0.916( \pm 0.059)$ & $5.0(1.0)$ & & & 7.1 \\
\hline S06 & 2.5 & $18.550( \pm 1.144)$ & $0.740( \pm 0.035)$ & $6.5(1.0)$ & & & 7.6 \\
\hline S09 & 2.5 & $2.959( \pm 0.441)$ & $0.577( \pm 0.066)$ & $6.5(1.0)$ & & & 6.7 \\
\hline S13 & 3.0 & $1.247( \pm 0.266)$ & $0.689( \pm 0.076)$ & $6.3(0.2)$ & $6.5 \quad(0.6)$ & $6.7(0.2)$ & 5.8 \\
\hline S14A & 2.5 & $4.378( \pm 0.657)$ & $0.638( \pm 0.067)$ & $6.5(1.0)$ & & & 6.5 \\
\hline S14B & 3.5 & $2.385( \pm 0.338)$ & $0.593( \pm 0.056)$ & $7.4(0.2)$ & $7.6(0.6)$ & $7.8(0.2)$ & 7.5 \\
\hline S15 & 3.5 & $9.262( \pm 0.8031)$ & $0.658( \pm 0.045)$ & $7.4(0.2)$ & $7.6(0.6)$ & $7.8(0.2)$ & 6.6 \\
\hline S16 & 3.5 & $9.885( \pm 0.828)$ & $0.644( \pm 0.039)$ & $7.0(1.0)$ & & & 8.2 \\
\hline S17 & 3.5 & $1.328( \pm 0.293)$ & $0.520( \pm 0.086)$ & $6.5(1.0)$ & & & 7.2 \\
\hline S17B & 3.5 & $3.790( \pm 0.516)$ & $0.681( \pm 0.070)$ & $7.3(0.2)$ & $7.5(0.6)$ & $7.7(0.2)$ & 7.2 \\
\hline
\end{tabular}

* Cumulative rate (event/year) of earthquakes with magnitude $\geqq m_{0}$.

** Number in parentheses is one standard deviation of estimation.

*** Number in parentheses is the relative weights of $m_{u}$.

(b) Characterization of subduction intraslab source

\begin{tabular}{|c|c|c|c|c|c|c|c|c|}
\hline Source code & Depth range & $m_{o}{ }^{*}$ & $\dot{N}\left(m_{o}\right)\left[ \pm \sigma_{\dot{N}\left(m_{o}\right)}\right]^{* *}$ & $b\left( \pm \sigma_{b}\right)^{* *}$ & & $\boldsymbol{m}_{u}{ }^{* * *}$ & & Largest recorded $M_{W}$ \\
\hline NP1 & $35 \sim 50 \mathrm{~km}$ & 4.0 & $3.000( \pm 0.318)$ & $0.849( \pm 0.077)$ & $7.6(0.2)$ & $7.7(0.6)$ & $7.8(0.2)$ & 7.4 \\
\hline NP2 & $50 \sim 70 \mathrm{~km}$ & 4.0 & $2.441( \pm 0.294)$ & $0.826( \pm 0.085)$ & $7.6(0.2)$ & $7.7(0.6)$ & $7.8(0.2)$ & 8.2 \\
\hline NP3 & $70 \sim 90 \mathrm{~km}$ & 4.0 & $1.313( \pm 0.214)$ & $0.778( \pm 0.097)$ & $7.6(0.2)$ & $7.7(0.6)$ & $7.8(0.2)$ & 7.2 \\
\hline NP4 & $90 \sim 110 \mathrm{~km}$ & 4.0 & $0.576( \pm 0.133)$ & $0.797( \pm 0.068)$ & $7.7(0.2)$ & $7.8(0.6)$ & $7.9(0.2)$ & 7.3 \\
\hline NP5 & $110 \sim 130 \mathrm{~km}$ & 4.0 & $0.309( \pm 0.103)$ & $0.824( \pm 0.071)$ & $7.7(0.2)$ & $7.8(0.6)$ & $7.9(0.2)$ & 7.6 \\
\hline NP6 & $130 \sim 150 \mathrm{~km}$ & 4.0 & $0.282( \pm 0.0998)$ & $0.861( \pm 0.071)$ & $7.7(0.2)$ & $7.8(0.6)$ & $7.9(0.2)$ & 6.0 \\
\hline NP7 & $150 \sim 170 \mathrm{~km}$ & 4.0 & $0.409( \pm 0.118)$ & $0.801( \pm 0.070)$ & $7.7(0.2)$ & $7.8(0.6)$ & $7.9(0.2)$ & 7.6 \\
\hline NP8 & $170 \sim 190 \mathrm{~km}$ & 4.0 & $0.410( \pm 0.114)$ & $0.894( \pm 0.070)$ & $7.7(0.2)$ & $7.8(0.6)$ & $7.9(0.2)$ & 5.4 \\
\hline NP9 & $>190 \mathrm{~km}$ & 4.0 & $0.870( \pm 0.174)$ & $0.884( \pm 0.067)$ & $7.7(0.2)$ & $7.8(0.6)$ & $7.9(0.2)$ & 5.9 \\
\hline
\end{tabular}

* Cumulative rate (event/year)of earthquakes with magnitude $\geqq m_{o}$.

** Number in parentheses is one standard deviation of estimation.

*** Number in parentheses is the relative weights of $m_{u}$.

(c) Characterization of subduction interface source

\begin{tabular}{|c|c|c|c|c|c|c|c|c|c|}
\hline Source code & $m_{o}$ & Slip rate $\left(\mathbf{m m} \mathbf{y r}^{-1}\right)$ & Dip (degree) & Seismogenic depth & $b$ & & $m_{u}$ & & Largest recorded $M_{W}$ \\
\hline T01 & 6.5 & $\begin{array}{l}30(0.2) \\
40(0.6) \\
50(0.2)\end{array}$ & $\begin{array}{l}18(0.3) \\
20(0.4) \\
22(0.3)\end{array}$ & $10 \sim 40 \mathrm{~km}$ & 0.7 & $7.8(0.2)$ & $8.0(0.6)$ & $8.2(0.2)$ & 6.2 \\
\hline
\end{tabular}

\footnotetext{
* The relative weights shown in parentheses.
} 
dance with the major geological inland boundaries and major seismogenic structures along the east coast and offshore of the northeast tip of Taiwan (Cheng 2002). For example, sources S14A, S14B and S15 represent the seismicity associated with the process of the opening of the Okinawa Trough, while sources S17A and S17B represent the seismicity of the active collision between the EP and the PSP. Taipei metropolis lies within the areal source S04, for which the maximum earthquake magnitude recorded in the last century is less than $\mathrm{M}_{\mathrm{w}} 6.0$ (shown in Table 1). According to the parameters of the truncated-exponential model (shown in Table 1), the return period of $\mathrm{M}_{\mathrm{W}} 6$ for crustal areal source S04 would be around 170 years. The other closest high recurrence rate source would be for S14A near S04, where the earthquake return period of $\mathrm{M}_{\mathrm{W}} 6.0$ for crustal areal source S14A would be approximately 40 years. In this study, the crustal areal sources near Taipei are assumed to fault randomly, so it is suggested that the spatial distribution of small to moderate earthquakes would be uniform within these crustal areal sources.

\subsection{Intraslab Earthquake Sources}

The geometry of the subduction zone plate can be delineated from well located seismicity data. The top surface of the subducting PSP is shown in Fig. 3. The subducting PSP reaches a depth of about $90 \mathrm{~km}$ under metropolitan. The closest distance from Taipei to the top of the subducting slab is about $60 \mathrm{~km}$, therefore, earthquakes occurring in this slab could contribute significantly to a seismic hazard in the Taipei region. Also, the slow rate of ground motion attenuation with distance would increase the level of hazard at a site, as well as increasing ground motion with increasing focal depth for a given earthquake magnitude. The source-to-site distance also increases the hazard (Crouse 1991; Youngs et al. 1997; Lin and Lee 2008). Utmost attention should be given to the intraslab earthquake sources in any evaluation of seismic hazard. A list of parameters for the truncated-exponential model of intraslab earthquake sources is shown in Table $2 b$.

In PSHA, the intraslab earthquake sources were divided into 9 zones of different depths (NP1 - NP9 as shown in Fig. 3). The dependence of PGA on focal depth could be approximated by separating several segments of slab according to depth. The average depth of each segment could then be used as the nominal focal depth to predict ground motion (Cheng et al. 2007). Several earthquakes with magnitudes greater than $\mathrm{M}_{\mathrm{W}} 7.0$ occurred in the intraslab sources in the last century (1909/04/15, 1910/4/12, 1920/6/23). The most important intraslab source is NP3, which at its closest is, approximately $60 \mathrm{~km}$ from the top of the intraslab source of the PSP to Taipei. The return period of an $\mathrm{M}_{\mathrm{W}} 6.0$ earthquake in NP3 would be around 30 years, as calculated from the parameters of truncated-exponential model (shown in
Table 2). In this study, it is assumed that the intraslab sources under the Taipei metropolis fault randomly so the spatial distribution of small to moderate earthquakes within these crustal areal sources would be uniform.

\subsection{Interface Earthquake Sources}

The depth to the plate interface between the EP and the subducting PSP is also shown by isobaths in Fig. 3. The fourth group (T01) represents thrust earthquakes on the plate interface and can extend from a depth of 10 to $40 \mathrm{~km}$. A list of characteristic-earthquake model parameters for interface earthquake sources is shown in Table 2c.

In a typical subduction zone, the plate interface is the locus of coseismic deformation and this is where instruments generally record the largest earthquakes in the world. The seismogenic width of the plate interface along most of the plate boundary is interpreted to behave in a stick-slip manner, whereby accumulated elastic seismic strain energy is released suddenly during the earthquake. From seismicity data, Kao (1998) inferred that the plate interface between the Ryukyu arc and Taiwan has a variable dip angle and span with a depth of about 15 to $35 \mathrm{~km}$. The largest reported earthquake along this portion of the plate interface (T01) over the past 100 years was $M_{W} 8.2$ and occurred in 1920 . Because the nature of this earthquake is not evident, it is uncertain whether $\mathrm{M}_{\mathrm{W}} \geqq 8$ events ever occurred along this segment of the interface. On the other hand, Kao (1998) had argued that the southernmost Ryukyu arc to Taiwan region is unlikely to generate $\mathrm{M}_{\mathrm{W}} \geqq 8$ interface earthquakes. He considered that the maximum magnitude of future events in this segment would be in the range of $\mathrm{M}_{\mathrm{w}}$ 7.6 to 7.7. The possibility of $\mathrm{M}_{\mathrm{W}} \geqq 8$ earthquakes occurring along the plate interface has been taken into account in this PSHA.

\section{GROUND-MOTION CHARACTERIZATION}

The Taipei Basin is filled with unconsolidated sediments. The subsurface soil layers consist of, in descending order, surface soil, the Shungshan Formation (Holocene silt and sand, about $50 \mathrm{~m}$ thick), the Chingmei Formation (Late Pleistocene sandy gravels, about $30 \mathrm{~m}$ thick), and the Hsinchung Formation (Middle to Late Pleistocene silt, sand, gravel, and paleosol up to about $700 \mathrm{~m}$ depth). The Shungshan Formation is the control layer for dynamic site response.

The recent local empirical ground motion attenuation relationships of PGA with magnitude in $\mathrm{M}_{\mathrm{W}}$ for different tectonic settings (crustal areal source, subduction zone) and different site conditions (rock, soil) are listed in Table 3. The attenuation relationships applied to soil conditions were selected for the PSHA evaluation of the seismic hazard in this area. The selected attenuation relationships for crustal earthquakes can be referred to in Lin et al. (2002). The pat- 
Table 3. Peak ground acceleration attenuation relationships for specific tectonics and site conditions in Taiwan, and adopted in PSHA of this study.

\begin{tabular}{llcc}
\hline Specific tectonics and site conditions & PGA attenuation relationship & $\boldsymbol{\sigma}_{\text {Iny }}$ & Ref. \\
\hline Rock, crustal source, hanging wall & $\ln y=-3.25+1.075 M_{W}-1.723 \ln \left[R+0.156 \exp \left(0.62391 M_{W}\right)\right]$ & 0.577 \\
Soil, crustal source, hanging wall & $\ln y=-2.80+0.955 M_{W}-1.583 \ln \left[R+0.176 \exp \left(0.603285 M_{W}\right)\right]$ & 0.555 \\
Rock, crustal source, foot wall & $\ln y=-3.05+1.085 M_{W}-1.773 \ln \left[R+0.216 \exp \left(0.611957 M_{W}\right)\right]$ & 0.583 \\
Soil, crustal source, foot wall & $\ln y=-2.85+0.975 M_{W}-1.593 \ln \left[R+0.206 \exp \left(0.612053 M_{W}\right)\right]$ & 0.554 \\
\hline Rock, subduction zone interface & $\ln y=-2.5+1.205 M_{W}-1.905 \ln \left[R+0.51552 \exp \left(0.63255 M_{W}\right)\right]+0.0075 H$ & 0.526 \\
Soil, subduction zone interface & $\ln y=-0.9+1.000 M_{W}-1.900 \ln \left[R+0.99178 \exp \left(0.52632 M_{W}\right)\right]+0.004 H$ & 0.627 \\
Rock, subduction zone intraslab & $\ln y=-2.5+1.205 M_{W}-1.905 \ln \left[R+0.51552 \exp \left(0.63255 M_{W}\right)\right]+0.0075 H+0.275 z_{t}$ & 0.526 & $(2008)$ \\
Soil, subduction zone intraslab & $\ln y=-0.9+1.000 M_{W}-1.900 \ln \left[R+0.99178 \exp \left(0.52632 M_{W}\right)\right]+0.004 H+0.31 z_{t}$ & 0.627 \\
\hline
\end{tabular}

Note: $M_{W}=$ moment magnitude; $R=$ closest distance to fault rupture plane $(\mathrm{km}) ; H=$ focal depth $(\mathrm{km}) ; y=P G A(\mathrm{~g}) ;$ intraslab $z_{t}=1$, interface $z_{t}=0$.

tern of the intensity map for the Chi-Chi earthquake suggests that the hanging wall effect should be considered in seismic hazard estimations for certain faults. Thus, the type of fault rupture, hanging wall $(\mathrm{HW})$ or foot wall $(\mathrm{FW})$, were identified for each site. The attenuation relationships were thus divided into HW and FW types. Soil attenuation relationships selected for the subduction zone earthquakes sources can be found in Lin and Lee (2008). Given similar earthquake magnitude and source to site distance, higher ground motion level is always observed, regardless of ground motion data set of global or Taiwan subduction zone sources (Lin and Lee 2008).

A comparison of the predicted median horizontal PGA of different attenuation relationships for soil sites is shown in Fig. 4. Not only are the attenuation relationships shown in Table 3 plotted, but also the attenuation relationship established by Loh et al. (2000) and Youngs et al. (1997). The former includes the 1999 Chi-Chi earthquake data and is calculated using an attenuation equation widely used in Taiwan. However, there was no differentiation between ground motion data caused by crustal earthquakes and subduction zone earthquakes. In addition, $\mathrm{M}_{\mathrm{L}}$ rather than $\mathrm{M}_{\mathrm{W}}$ was used to represent earthquake magnitude. Youngs et al. (1997) derived the attenuation relationships for global subduction zone earthquakes from data sets from Japan, Mexico, and Chile. Figure 4 shows that subduction zone earthquakes (Lin and Lee 2008) have significantly higher levels of groundmotion than crustal ones (Lin et al. 2002), although the level of ground-motion in Taiwan subduction zone earthquakes is lower than that of global subduction zone earthquakes. It also shows that ground-motion prediction of HW is higher

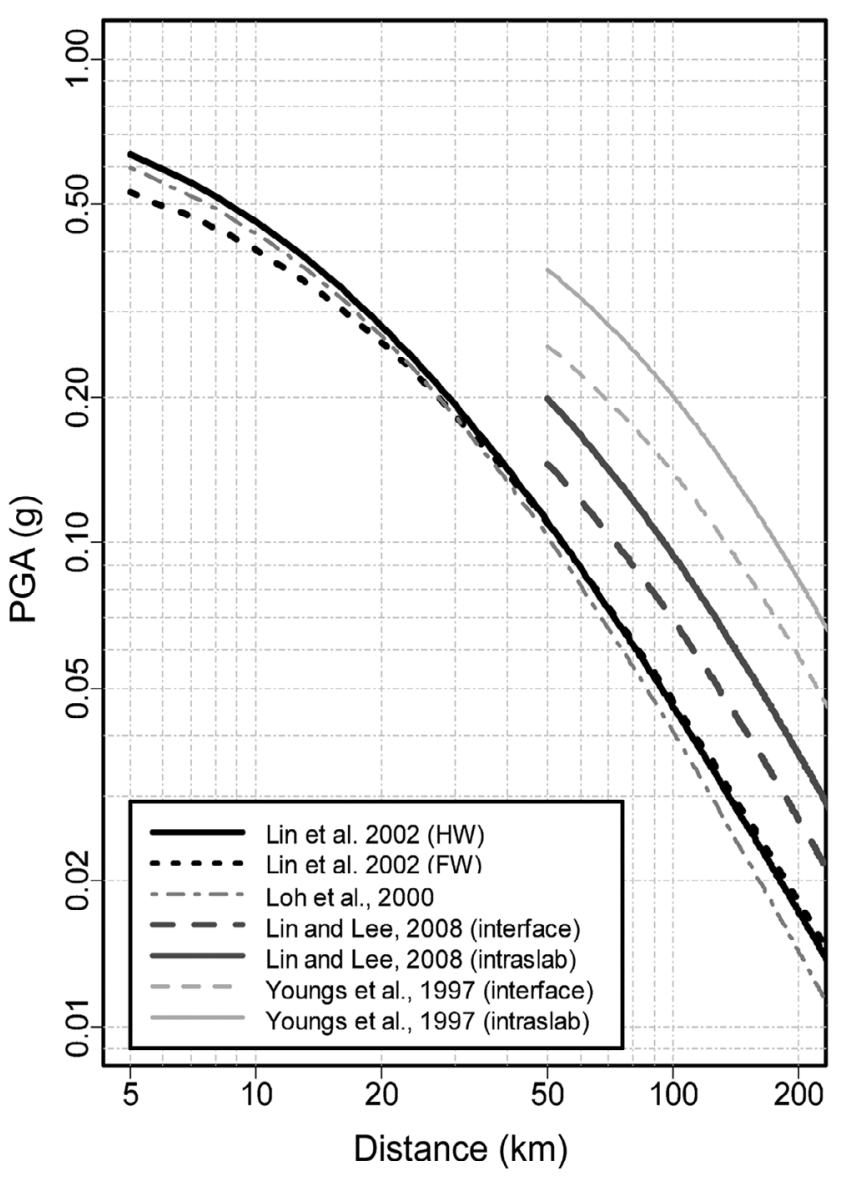

Fig. 4. Comparison of peak ground accelerations in a soil site condition predicted from the five attenuation relationships with magnitude of $\mathrm{M}_{\mathrm{W}} 7.6$ and a focal depth of $50 \mathrm{~km}$. Lin et al. (2002) (HW/FW) and Lin and Lee (2008) (interface/intraplate) are the ground-motion attenuation relationships used in this study. See text for more description. 
than FW when the distance from the fault rupture plane is less than $30 \mathrm{~km}$. This phenomenon is indeed implied from the experience of the Chi-Chi Earthquake, where the ground motion was higher on the hanging wall of the Chelungpu fault rupture plane than on the footwall side.

The Shanchiao fault is located along the northwestern margin of metropolitan Taipei with an approximately 60SE dip (Wang and Sun 1999). Hence, Taipei is almost on the hanging wall of the fault. This may lead to a higher level of ground-motion than previously estimated. It is thus very important to apply the appropriate ground-motion attenuation relationship in the PSHA.

\section{PSHA PROCEDURE}

The PSHA procedure used in this study mainly depends on the Taiwan seismic hazard model proposed by Campbell et al. (2002) and Cheng (2002). In this PSHA, fault-specific sources (active faults and subduction interface) are used to represent a specific geologic structure or fault. These sources are modeled as segmented planar features with their geometry represented by the fault trace, fault dip, and depth range where it is assumed that future earthquakes will occur. After earthquake source zone identification (as shown in Tables 1 and 2), two earthquake recurrence models are adopted to estimate the recurrence rate of each earthquake source. The first one is the truncated-exponential model developed from the mainshock catalog (in $\mathrm{M}_{\mathrm{w}}$ ) from 1900 through 1999. This is used to depict the recurrence of earthquakes triggered by crustal areal and intraslab sources. The second one is the characteristic-earthquake model estimated by the fault slip rate, which is used to describe the earthquake recurrence frequency of active fault and subduction interface sources. For the characterization of the four earthquake sources (crustal areal sources, active faults, interface, and intraslab) refers to Lee (1999), Cheng (2002), and Cheng et al. (2007). Their source parameters are shown in Table 2. For easy handling and access during the PSHA, the parameters and information on seismogenic sources and active faults mentioned above were incorporated and integrated into GIS (Cheng et al. 1998).

The appropriate attenuation relationships were applied to predict the peak ground motion of crustal and subduction zone earthquakes individually. The ground-motion attenuation relationships adopted in this study are shown in Table 3 . The truncation of the predicted ground-motion distribution (at $2 \sigma_{\text {lny }}$ ) of the attenuation relationships has been recommended by the USGS for conservative engineering design in the United States (NRC 1988; Petersen et al. 2008). We adopted the same truncation method for conducting the PSHA of the Taipei area.

After setting the parameters for earthquake sources and attenuation relationships as input for this PSHA, the logic tree methodology was employed to incorporate uncertainty into the modeling. The logic tree formulation for seismic hazard analysis involves setting out the sequence of assessment that must be made in order to perform the analysis, addressing the uncertainty in each of these assessments in a sequential manner (NRC 1988; Cheng et al. 2007). This provides a convenient approach for breaking a large, complex assessment into a sequence of smaller, simpler components that can be addressed more easily. The logic tree method was thus used to address the uncertainty of source type, attenuation relationships, focal depth, earthquake recurrence model, and fault geometry was addressed in this study. The mathematical formulation and PSHA approach developed by Cornell (1968) and the NRC (1988) were adopted for calculating the PSHA for the Taipei area. For a detailed description of the utilization of the logic tree technique for addressing the uncertainty of input parameter of Taiwan PSHA model please refer to Cheng (2002) and Cheng et al. (2007).

The seismic hazard was computed and the results summarized given the size of earthquakes from minimum magnitude $m_{o}$ to maximum $m_{u}$ in each seismogenic zone. For each level of ground motion, a complete set of hazard values was computed over all end branches of the logic tree to form a discrete distribution for frequency of exceedance. The computed distributions were used to obtain the mean frequency of exceeding each level of peak ground motion (forming the mean hazard curve) as well as hazard curves representing the various percentiles of the distributions. The seismic hazard logic tree represents our best judgment of the uncertainty in defining the input parameters. Hence, the computed distributions represent our confidence interval for the estimated hazard. The total probability of seismic hazard of specific PGA level is integrated from the probability of exceedance of surrounding earthquake sources of different magnitudes, distance and epsilon $(\varepsilon)$ intervals. In addition, the meaning of $\varepsilon$ is the expected PGA level scaled to the number of standard deviation of ground motion relationship. In contrast, the total probability of seismic hazard could be de-aggregated into numbers of subgroup sources in different bins of magnitude, distance and epsilon $(\varepsilon)$. Furthermore, it is easy to rank the hazard contribution of each subgroup source, and then pick out the most important for seismic hazard mitigation using deaggregation analysis (Harmsen and Frankel 2001; Cheng et al. 2007).

\section{RESULTS OF PSHA AND DEAGGREGATION}

After PSHA is performed at each regular grid point in the study area, probabilistic seismic hazard mapping can be done. A PGA map of 475-year return period and a PGA map of 2475-year return period for soil site condition are shown in Fig. 5 for example and for further discussion.

The PGA seismic hazard levels in Taipei and the surrounding region are around 0.25 to $0.35 \mathrm{~g}$ for a 475 -year return period and 0.40 to $0.50 \mathrm{~g}$ for a 2475 -year return pe- 
(a)



(b)
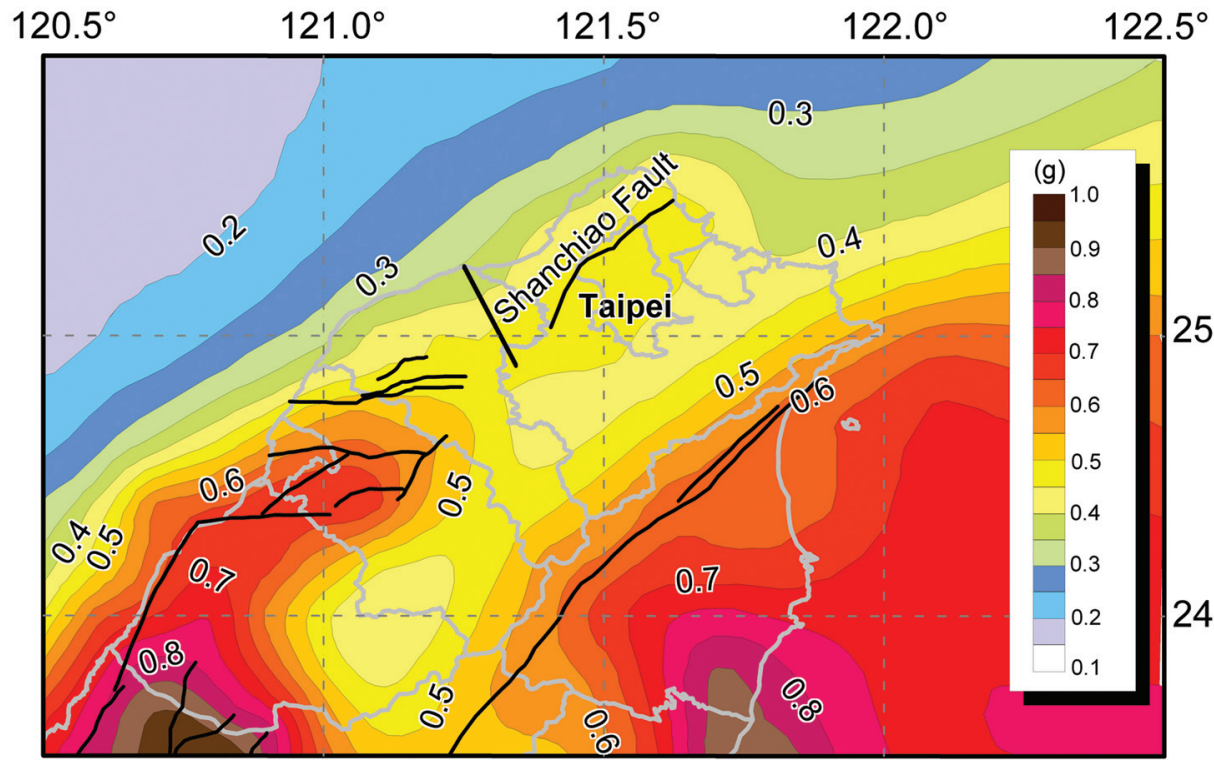

Fig. 5. Seismic hazard map of PGA was conducted for Taipei metropolis and northern Taiwan region in soil site condition. PGA with a (a) $10 \%$ and (b) $2 \%$ chance of exceedance in 50 years is depicted in unit of g. Black lines indicate active faults used in this study.

riod. The seismic hazard maps reveal that the hazard level increases from the northwest to the southeast and southwest. This feature could be due to the contribution of subduction zone earthquakes and the high activity in faults in central Taiwan. Comparing the results in Figs. 5a and b, it can be seen that the Shanchiao fault contributes significantly to the hazard level in the long return period.

Seismic hazard curves for soil site condition at downtown Taipei City are illustrated in Fig. 6. The PSHA seismic hazard curves show the total hazard in the $5^{\text {th }}, 50^{\text {th }}$ (median), and $95^{\text {th }}$ percentiles of uncertainty. The 90 percent confident interval of total hazard would be the interval bounded by the $5^{\text {th }}$ and $95^{\text {th }}$ percentiles in the figure. The hazard contri- bution from various sources around Taipei to total hazard is also indicated in Fig. 6. This reveals that the intraslab earthquake source contributes a much greater probability to total seismic hazard. The high rate of recurrence of largemagnitude intraslab earthquake and the large peak ground motion experienced in soil sites from intraslab earthquakes can be explained and understood (Cheng 2002). The minor contribution of areal crustal sources to the overall seismic hazard lies in the regions of S14B and S14A. In this region, even though the Shanchiao fault dominates the seismic hazard for the long return period (such as 2475-year), it makes minor contributions for the short return period (the less than 475-year return period). 
The total seismic hazards in Taipei City are deaggregated in bins of magnitude, distance and epsilon $(\varepsilon)$, as shown in Fig. 7. The deaggregated hazard results of PGA hazard analysis indicate that the hazard contributions come primarily from subduction zone sources at $60 \mathrm{~km}$, for events with a magnitude close to 7.8 in a 50 -year return period. In a 475 -year return period, the hazard is affected by nearby areal crustal sources, fault sources and subduction zone sources. On the other hand, in a 2475 -year return period, the seismic hazard contribution comes totally from the closest fault (Shanchiao fault).

It should be noted that one can realize the distance of a disastrous earthquake and its magnitude in metropolitan Taipei and surrounding regions from deaggregation of the PSHA (shown in Figs. 8 and 9). In Fig. 8 it is shown where and how far away the earthquake contributing the major seismic hazard to the site is, while Fig. 9 shows how the magnitude of the earthquake near this location will affect the site. Overall, the distance of the dominating earthquake hazard increases in the northern part in the 50-year period.
The seismic hazard in the northeastern part is higher for events with magnitudes of about 7 to 8 . In the 2475-year period, the seismic hazard is associated with the adjacent Shanchiao fault. This type of deaggregation can assist engineers to quickly and clearly distinguish any possible earthquake hazard and its potential characteristics for different return periods.

\section{DISSCUSION}

The results of the present study are significantly more comprehensive than those of previous studies of the PGA level. For a 475-year return period Tsai et al. (1987) proposed a PGA level of $0.16 \sim 0.19 \mathrm{~g}, 0.20 \mathrm{~g}$ was proposed by Cheng (1997), and $0.23 \mathrm{~g}$ proposed by CPAMI (1999). Compared with these previous results, the seismic hazard level predicted in the present study is $50 \%$ to $80 \%$ larger. The major differences between the present study and previous studies are the following: (1) use of crustal fault sources; (2) use of subduction zone attenuation equations; and

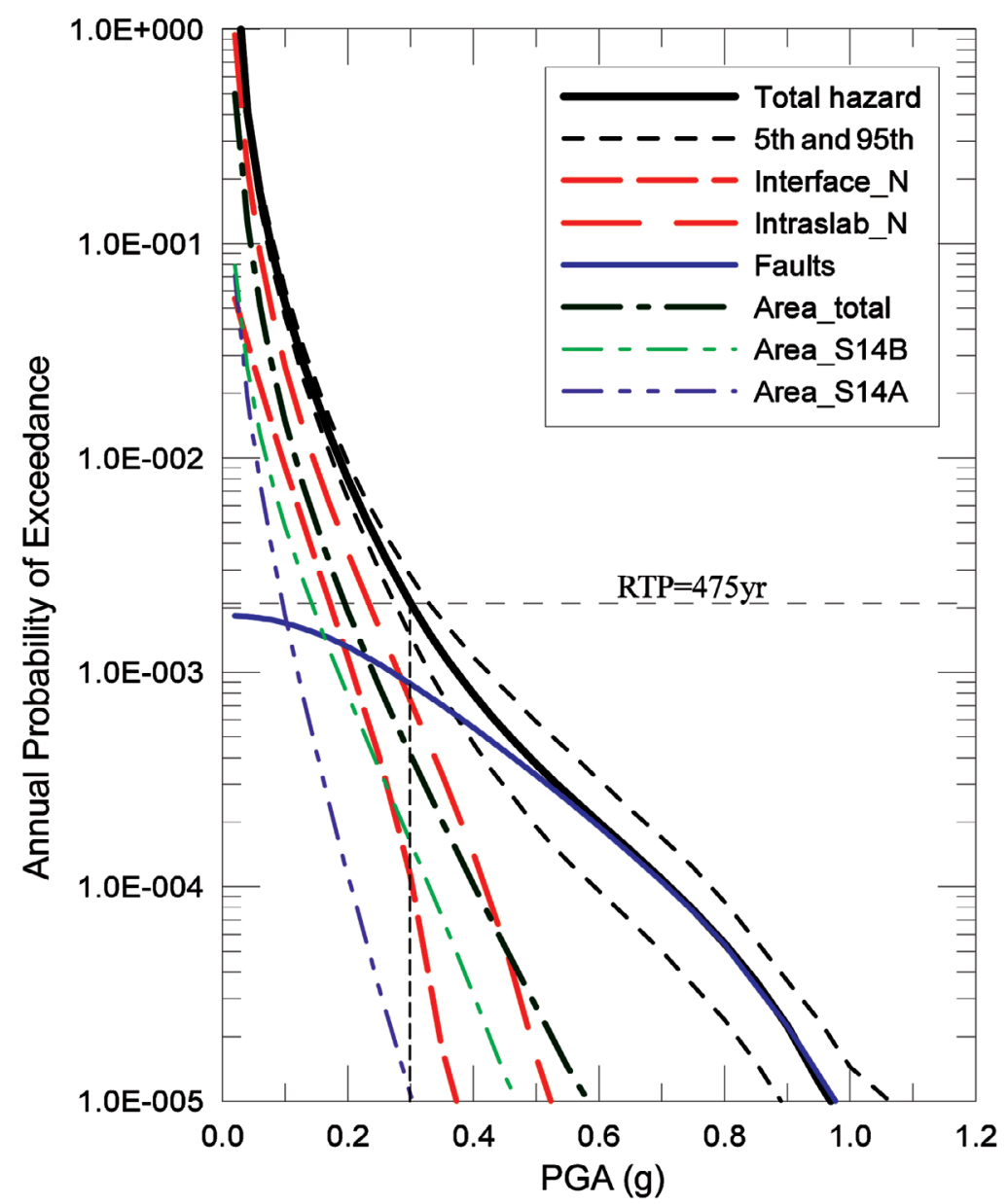

Fig. 6. Seismic hazard curves of PGA for Taipei city in soil site condition. The hazard curves of PGA present the total hazard in $5^{\text {th }}, 50^{\text {th }}(\mathrm{median})$, and $95^{\text {th }}$ percentiles uncertainty in PSHA. In addition, the hazard contribution from the sources around Taipei to total hazard(s) is also shown in the figure in different line styles. The horizontal dashed line indicates the annual probability of exceedance in 1/475 representing 475 -year return period, and the horizontal dashed line crosses over the total hazard curve at PGA $0.3 \mathrm{~g}$ is referred by a vertical dashed line. 
(a) $\mathrm{PE}=63.2 \%$ in $50 \mathrm{yr}, \mathrm{RTP}=50 \mathrm{yr}$
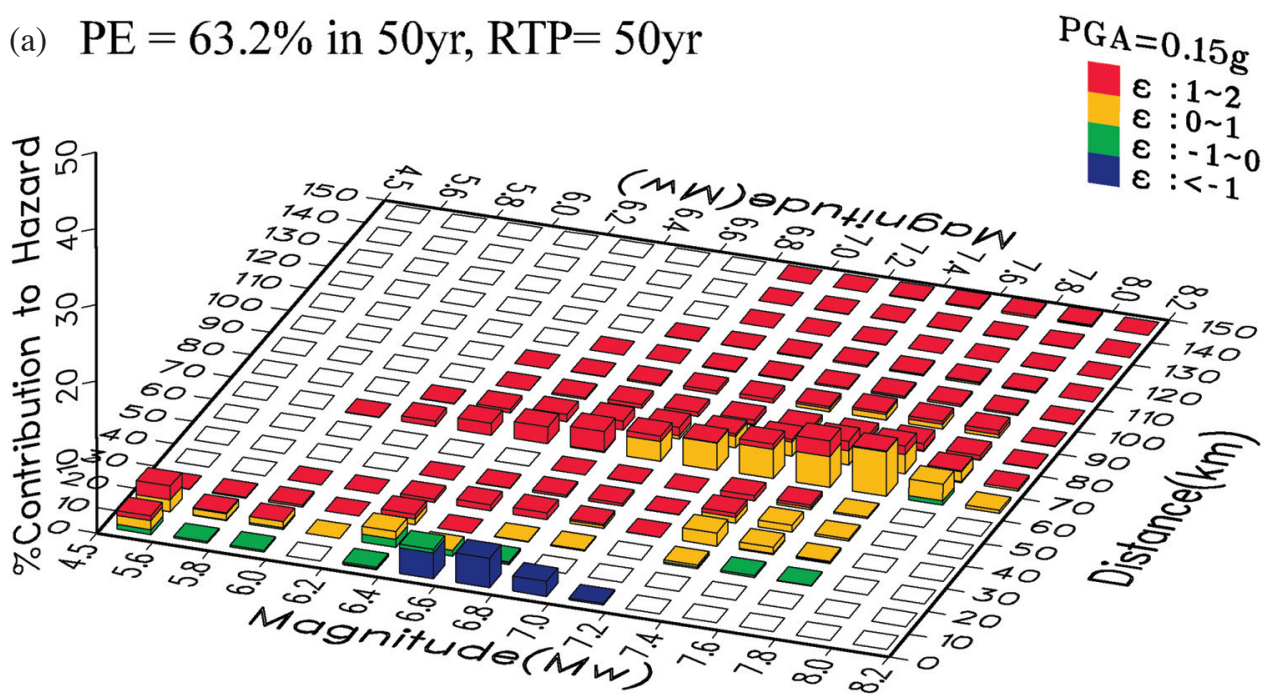

(b) $\mathrm{PE}=10 \%$ in $50 \mathrm{yr}, \mathrm{RTP}=475 \mathrm{yr}$

$\mathrm{PGA}=0.30 \mathrm{~g}$

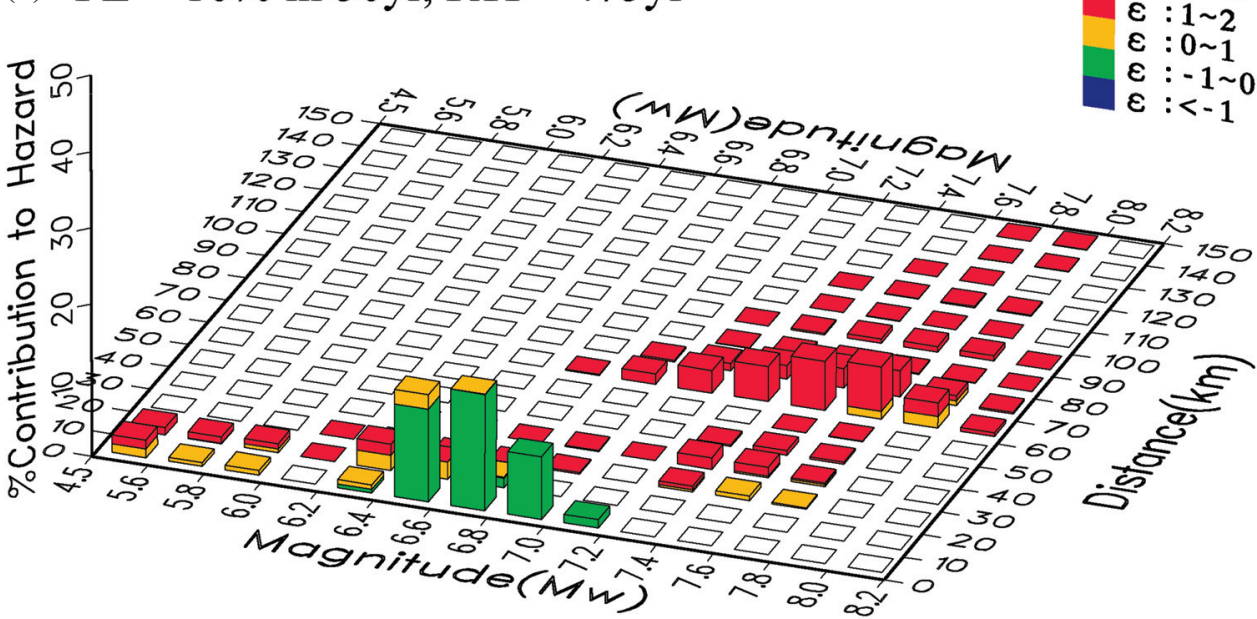

(c) $\mathrm{PE}=2 \%$ in $50 \mathrm{yr}, \mathrm{RTP}=2475 \mathrm{yr}$

$\mathrm{PGA}=0.49 \mathrm{~g}$

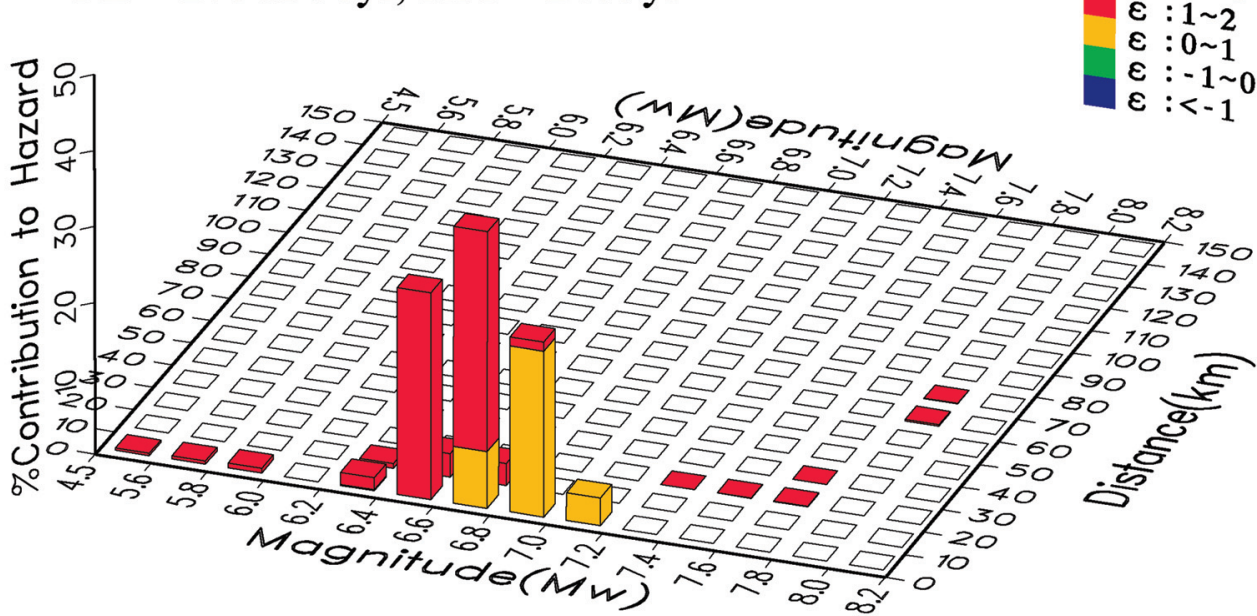

Fig. 7. Deaggregation of the total seismic hazard of Taipei in different Probability of exceedance (PE) and return period (RTP). (a) 50 yr return period; (b) $475 \mathrm{yr}$ return period; (c) $2475 \mathrm{yr}$ return period. The total seismic hazard is discrete in magnitude bins, distance bins and epsilon ( $\varepsilon$ ). The meaning of $\varepsilon$ is the expected PGA level scaled to number of standard deviation of ground motion relationship. 
(a)

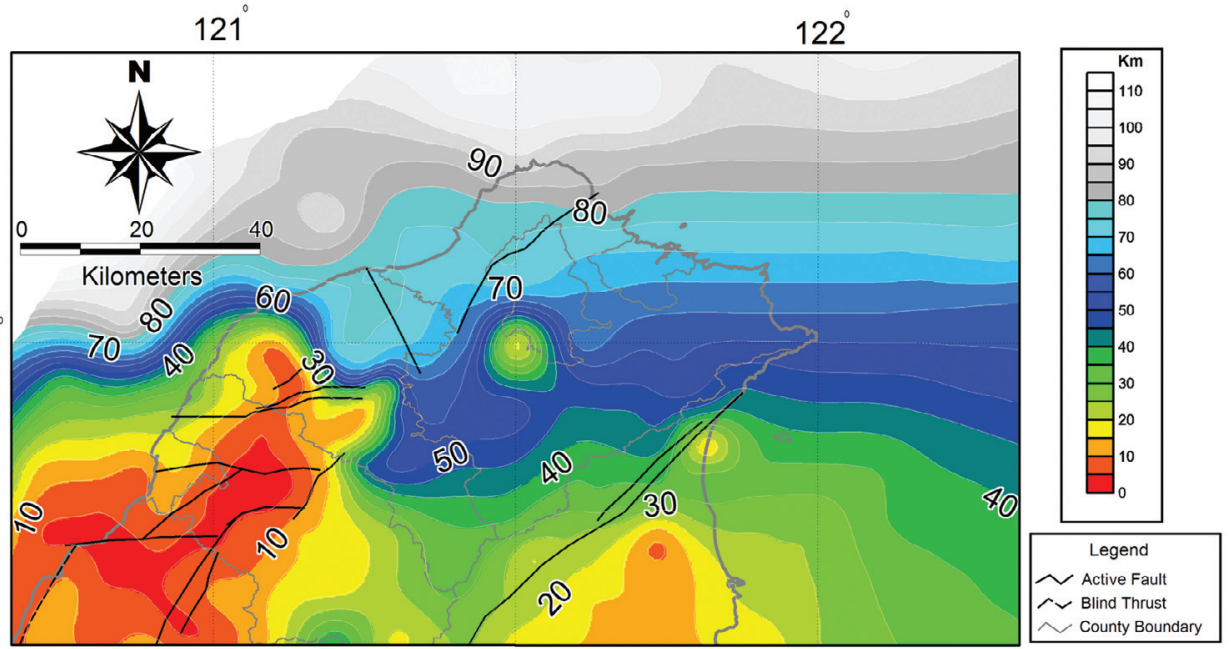

(b)

121

$122^{\circ}$
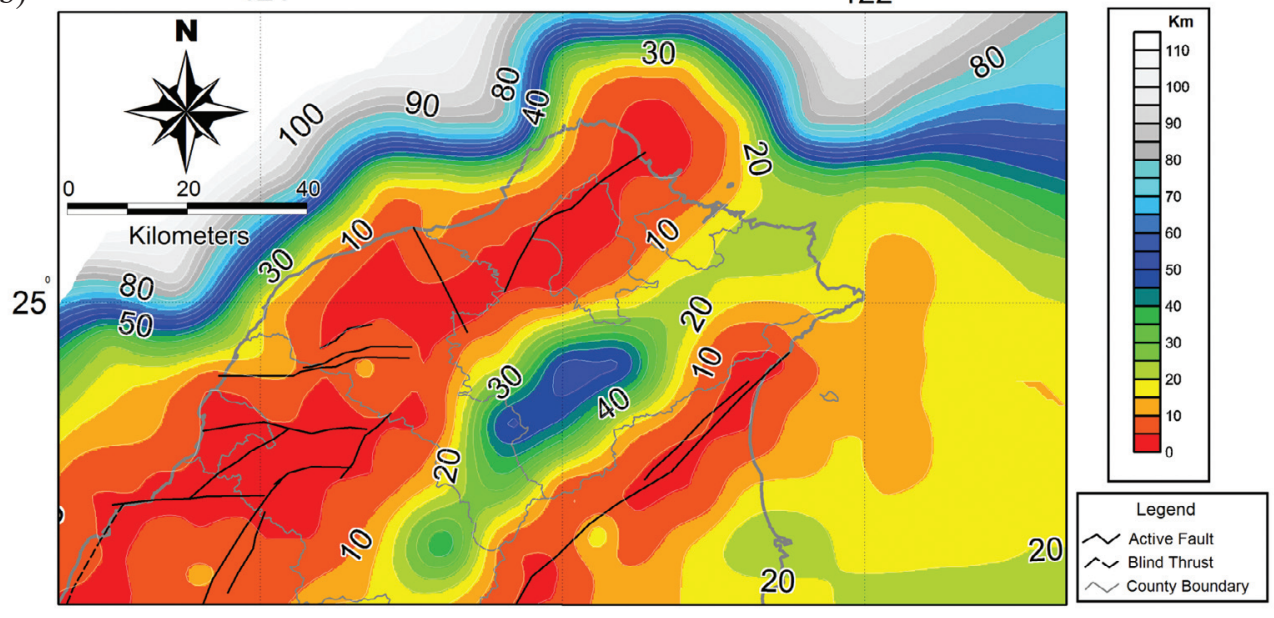

Fig. 8. Deaggregation of seismic hazard with distance bins in (a) RTP $=50 \mathrm{yr}$, and (b) RTP $=2475 \mathrm{yr}$.

(3) take into account ground-motion variability in PSHA. All these are used in the present study but not used in the previous studies. Let us examine Fig. 6 in this study. The hazard contribution from crustal fault sources is negligible in the 475-year return period; however, the hazard contribution from subduction intraslab sources is significant source. Therefore, we can presume that crustal fault sources may not play an important role in the 475-year hazard level, but that subduction intraslab sources do when combined with the subduction zone earthquake attenuation equations.

We can test this by replacing the subduction zone attenuation equations by the crustal attenuation equations used in this study. The results are shown in Fig. 10. It can be observed that the PGA level at downtown Taipei is reduced to about $0.25 \mathrm{~g}$. This $0.05 \mathrm{~g}$ reduction totally comes from the difference between the crustal attenuation equations and the subduction zone attenuation equations. However, this value is still higher than that found in previous studies. It is obvious that the inclusion of ground-motion variability in the
PSHA should increase the level of ground-motion (Bommer and Abrahamson 2006). Without considering the groundmotion variability, the PGA level for a 475-year return period would be reduced to about $0.2 \mathrm{~g}$, similar to the results of Cheng (1997).

Campbell et al. (2002) carried out an independent analysis of PSHA for Taiwan using a state-of-the-art approach similar to that used in the present study. The similarities include: adopting fault sources and subduction intraslab/ interface sources, using $\mathrm{M}_{\mathrm{w}}$ for earthquake magnitude, adding attenuation equations for subduction zone earthquakes, and accounting for ground-motion variability in the PSHA. The difference between their study and ours is that they assume rock site condition while we consider soil site condition. Campbell et al. (2002) obtained a value of about $0.25 \mathrm{~g}$ for downtown Taipei, while we obtained $0.3 \mathrm{~g}$ in the present study. However, if we assume soil site condition in our PSHA scheme, then we also obtain a PGA level also $0.25 \mathrm{~g}$, similar to that of Campbell et al. (2002). Because downtown 
(a)
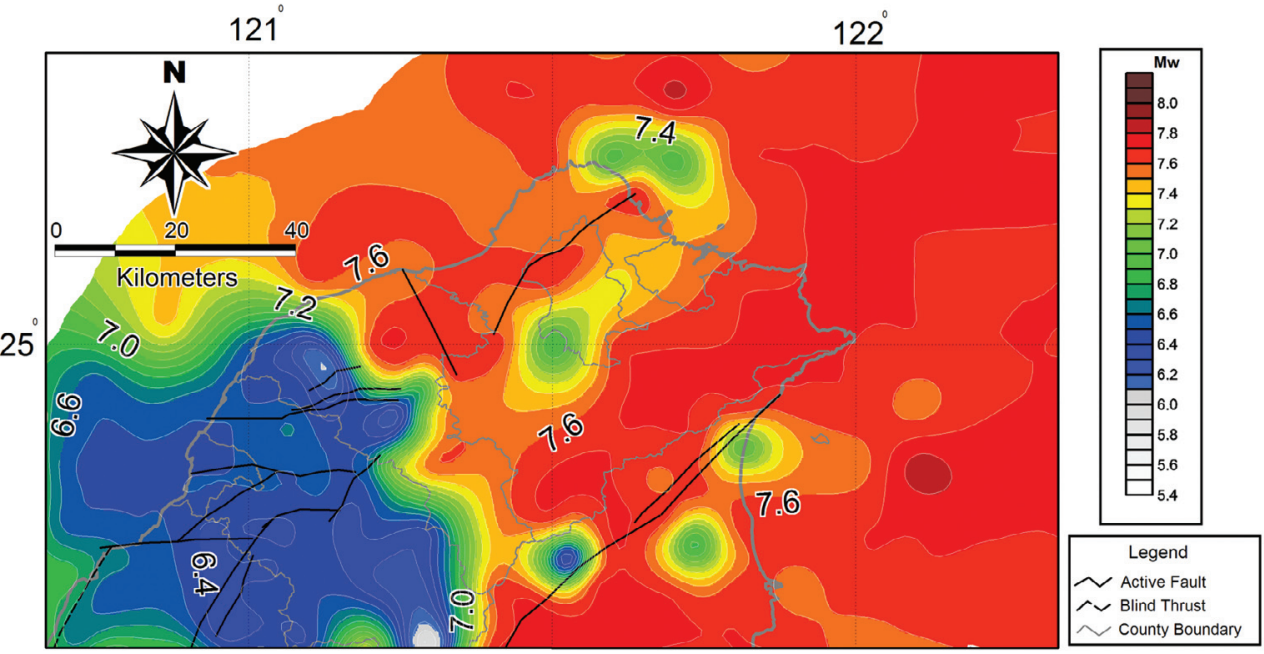

(b)

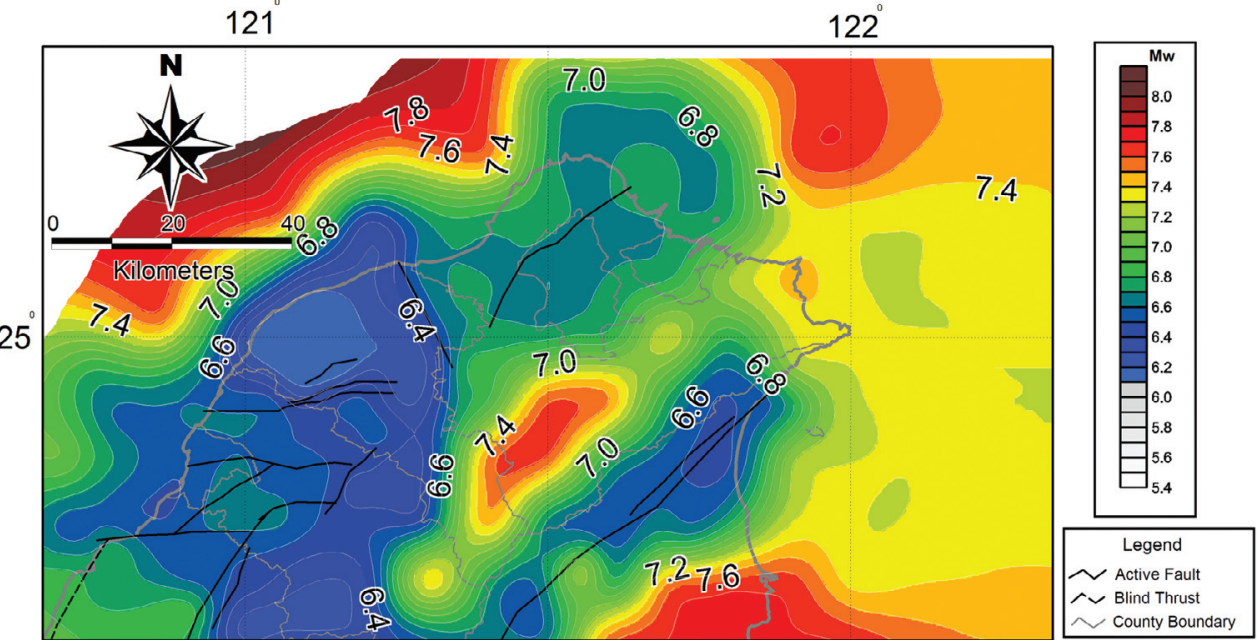

Fig. 9. Deaggregation of seismic hazard with magnitude bins in (a) RTP $=50 \mathrm{yr}$, and (b) RTP $=2475 \mathrm{yr}$.

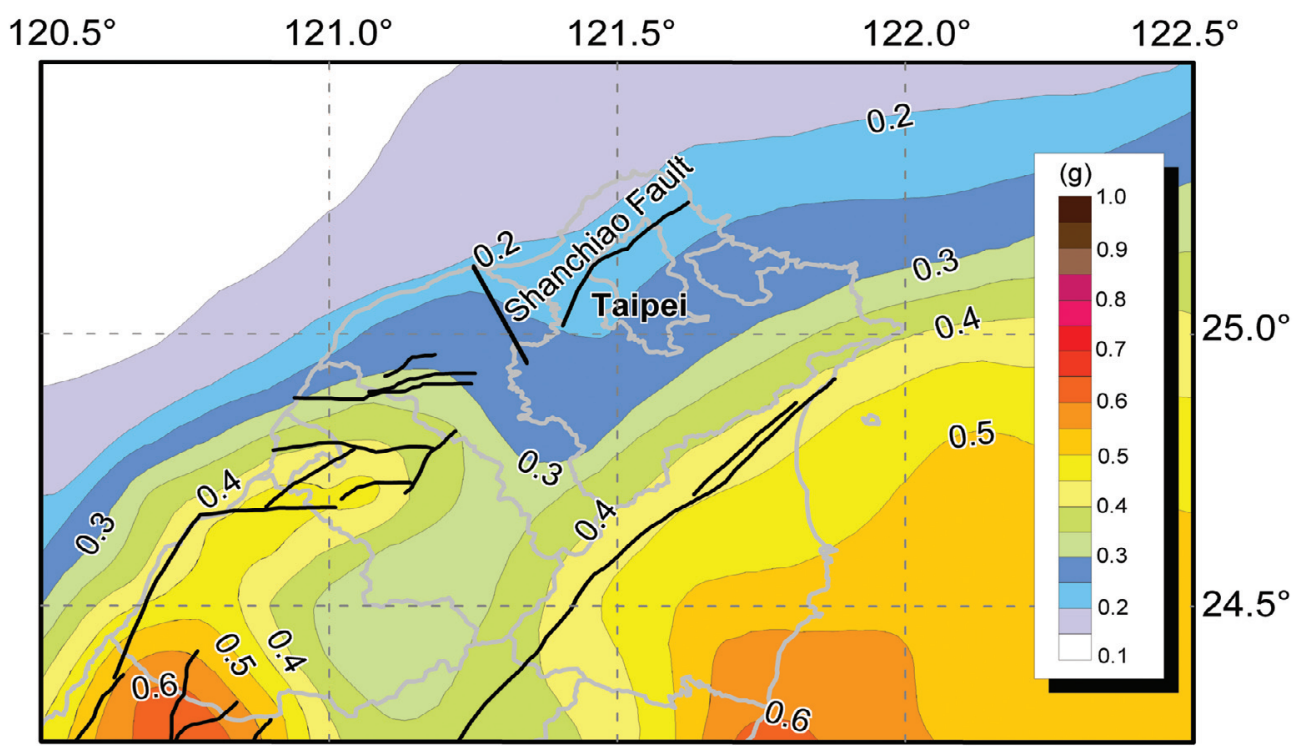

Fig. 10. Result of PSHA on 10\% Prob. of Exceedance in 50 years, if we replace the subduction zone attenuation equations by the crustal attenuation equations. 
Taipei actually locates at soil site, therefore, a PGA level of $0.3 \mathrm{~g}$ for a 475 -year return period is deemed reasonable and should be considered in modifications of the building code for metropolitan Taipei.

The Shanchiao fault has attracted the most attention for earthquake hazard analysis. However, this study reveals its contribution to the 475-year return period average hazard is slight. This is not surprising, for the fault has an estimated recurrence interval of 543 years. It becomes a controlling source in the 2475-year return period average hazard. However, we must realize that the current PSHA only provides an average time hazard and does not take into account the elapsed time of a fault source or the occurrence probability of a fault. To obtain a more accurate solution, a time-dependent PSHA (Cramer et al. 2000) should be performed in the future. Trenching and paleo-earthquake studies of the Shanchiao fault are needed to clarify the slip-rate/recurrenceinterval and elapsed time to better define the parameters for time-dependent PSHA.

The site response and basin effect were also not considered herein but these are important factors that should also be considered in future studies. These factors could include the average shear velocity at a depth of $30 \mathrm{~m}$ (Vs30)(Choi and Stewart 2005; Lee and Tsai 2008), the velocity structure of the Taipei Basin, and the site-dependent response spectral attenuation equations.

\section{CONCLUSIONS AND RECOMMENDATIONS}

The four major source groups in the northern Taiwan area include crustal areal sources, a nearby active fault, and interface and intraslab subduction zones. These dominate the seismic hazards in the Taipei metropolitan area. The PSHA results suggest that for the 475-year return period, the contribution of intraslab earthquakes to the seismic hazard is the most significant. Compared with the local Building Technical Code (CPAMI 1999), which suggests a PGA of $0.23 \mathrm{~g}$ in 475 -year return period, our result shows $0.3 \mathrm{~g}$ in downtown Taipei (see Fig. 5). The new value is $30 \%$ larger than specified in the code. This difference is clearly coming from the selection of ground motion attenuation for subduction zone earthquakes. Since the subducting slab is only $60 \mathrm{~km}$ distant to Taipei metropolis, any negative uncertainty would greatly influence the hazard level. Further study of ground motion attenuation for subduction earthquakes should be continued and results be compared with global data sets.

The crustal fault source of Fault No. 01+02+03 (the combined Huangchi, Hsiaoyukeng and Shanchiao faults) undoubtedly acts a significant hazard source in Taipei. It was found that the assembled fault makes the largest contribution to the seismic hazard in the long return period (2475 years) but not in the short return period (475 years). Consequently, the slip rate of fault segments, elapsed time, and maximum magnitude should be further studied and carefully estimated. Hopefully, time-dependent PSHA will be carried out.

The deaggregation results of PSHA show the seismic hazard contributed from individual distance and magnitude bins in different return periods. The deaggregation could provide better information for hazard mitigation in terms of choosing earthquakes scenarios for geohazard analysis, such as liquefaction, landslides, tsunamis, etc. Since a major subduction zone earthquake could lead to catastrophic damage to property and immense loss of life, it is suggested that more attention should be paid to subduction zone sources in hazard mitigation in the Taipei metropolitan area and northern Taiwan.

Acknowledgements The authors wish to express their thanks to the Central Weather Bureau for its assistance in providing the Taiwan earthquake catalogue and strong motion database of TSMIP. This research was supported by the Taiwan Earthquake Research Center (TEC) funded through the National Science Council (NSC), Grant No. NSC962119-M-008-004. The TEC contribution number for this article is 00060 .

\section{REFERENCES}

Big, C. C., 1972: Dual-trench structure in the Taiwan-Luzon region. Proc. Geol. Soc. China, 15, 66-75.

Campbell, K. W., P. C. Thenhaus, T. P. Barnhard, and D. B. Hampson, 2002: Seismic hazard model for loss estimation and risk management in Taiwan. Soil Dyn. Earthq. Eng., 22, 743-754, doi: 10.1016/S0267-7261 (02)00095-7. [Link]

Chan, Y. C., Y. G. Chen, T. Y. Shih, and C. Huang, 2007: Characterizing the Hsincheng active fault in northern Taiwan using airborne LIDAR data: Detailed geomorphic features and their structural implications. $J$. Asian Earth Sci., 31, 303-316, doi: 10.1016/j.jseaes.20 06.07.029. [Link]

Cheng, C. T., 2002: Uncertainty analysis and deaggregation of seismic hazards. Ph.D. Dissertation, National Central University, Jhongli, Taiwan, ROC, 197 pp. (in Chinese)

Cheng, C. T., C. T. Lee, and Y. B. Tai, 1998: Seismic hazard analysis assisted by a geographic information system. Sino-Geotechnics, 69, 41-50. (in Chinese)

Cheng, C. T., S. J. Chiou, C. T. Lee, and Y. B. Tai, 2007: Study on probabilistic seismic hazard maps of Taiwan after Chi-Chi earthquake. J. GeoEng., 2, 19-28.

Cheng, S. N. and Y. T. Yeh, 1989: Catalogue of earthquakes in Taiwan from 1604 to 1988. Open-File Report, Inst. Earth Sci., Acad. Sin., 255 pp. (in Chinese)

Choi, Y. and J. P. Stewart, 2005: Nonlinear site amplification as function of $30 \mathrm{~m}$ shear wave velocity. Earthq. 
Spectra, 21, 1-30, doi: 10.1193/1.1856535. [Link]

Coppersmith, K. J., 1991: Seismic source characterization for engineering seismic hazard analysis. Proceedings of the Fourth International Seismic Zonation Conference, 1, 1-60.

Cornell, C. A., 1968: Engineering seismic risk analysis. Bull. Seismol. Soc. Am., 58, 1583-1606.

CPAMI (Construction and Planning Agency Ministry of the Interior), 1999: Building Technical Regulations, 429 pp.

Cramer, C. H., M. D. Petersen, T. Cao, T. R. Toppozada, and M. Reichle, 2000: A time-dependent probabilistic seismic-hazard model for California. Bull. Seismol. Soc. Am., 90, 1-21, doi: 10.1785/0119980087. [Link]

Crouse, C. B., 1991: Ground motion attenuation equations for earthquakes on the Cascadia subduction zone. Earthq. Spectra, 7, 201-236, doi: 10.1193/1.1585626. [Link]

Davison, F. C. and C. H. Scholz, 1985: Frequency-moment distribution of earthquakes in the Aleutian Arc: A test of the characteristic earthquake model. Bull. Seismol. Soc. Am., 75, 1349-1361.

EERI (Earthquake Engineering Research Institute), 1989: The basics of seismic risk analysis. Earthq. Spectra, 5, 675-702, doi: 10.1193/1.1585549. [Link]

Frankel, A. D., M. D. Petersen, C. S. Mueller, K. M. Haller, R. L. Wheeler, E. V. Leyendecke, R. L. Wesson, S. C. Harmsen, C. H. Cramer, D. M. Perkins, and K. S. Rukstales, 2002: Documentation for the 2002 Update of the National Seismic Hazard Maps. Open-File Report 02-420, US Geological Survey.

Harmsen, S. and A. Frankel, 2001: Geographic deaggregation of seismic hazard in the United States. Bull. Seismol. Soc. Am., 91, 13-26, doi: 10.1785/0120000007. [Link]

Hsu, M. T., 1983: Estimation of earthquake magnitudes and seismic intensities of destructive earthquakes in the Ming and Ching eras. Meteorol. Bull., 29, 1-18.

Hu, J. C., S. B. Yu, and J. Angelier, 2001: Active deformation of Taiwan from GPS measurements and numerical simulations. J. Geophys. Res., 106, 2265-2280.

Huang, S. Y., C. M. Rubin, Y. G. Chen, and H. C. Liu, 2007: Prehistoric earthquakes along the Shanchiao fault, Taipei Basin, northern Taiwan. J. Asian Earth Sci., 31, 265-276, doi: 10.1016/j.jseaes.2006.07.025. [Link]

Kao, H., 1998: Can great earthquakes occur in the southernmost Ryukyu arc-Taiwan region. Terr. Atmos. Ocean. Sci., 9, 487-508.

Kao, H. and W. P. Chen, 2000: The Chi-Chi earthquake sequence: Active, out-of-sequence thrust faulting in Taiwan. Science, 288, 2346-2349, doi: 10.1126/science.288.5475.2346. [Link]

Lee, C. T., 1999: Neotectonics and active faults in Taiwan. Proceedings of the 1999 Workshop on Disaster Pre-
vention/Management and Green Technology, Foster City, California, 61-74.

Lee, C. T. and Y. Wang, 1988: Quaternary stress changes in northern Taiwan and their tectonic implications. Proc. Geol. Soc. China, 31, 154 -168.

Lee, C. T. and B. R. Tsai, 2008: Mapping Vs30 in Taiwan. Terr. Atmos. Ocean. Sci., 19, 671-682, doi: 10.3319/ TAO.2008.19.6.671(PT). [Link]

Lee, C. T., C. T. Cheng, and P. S. Lin, 2002: Recent advances on probabilistic seismic hazard analysis in Taiwan, 2002 Taiwan Rock Engineering Symposium, Hsin-Chu, 691-701.

Lin, P. S. and C. T. Lee, 2008: Ground-motion attenuation relationships for subduction zone earthquake in northeastern Taiwan. Bull. Seismol. Soc. Am., 98, 220-240, doi: 10.1785/0120060002. [Link]

Lin, P. S., C. T. Cheng, and C. T. Lee, 2002: Response spectral attenuation relations for shallow crustal earthquakes and subduction zone earthquakes in Taiwan, Proceedings of $9^{\text {th }}$ Taiwan Geophysical Meeting, 333-336.

Loh, C. H., Y. T. Yeh, W. Y. Jean, and Y. H. Yeh, 1991: Probabilistic seismic risk analysis in the Taiwan area based on PGA and spectral amplitude attenuation formulas. Eng. Geol., 30, 277-304, doi: 10.1016/00137952(91)90064-R. [Link]

Loh, C. H., K. L. Wen, W. Y. Jean, J. F. Chai, T. J. Teng, R. J. Rau, 2000: The Seismic Force Requirements considering near-fault effect and uniform hazard. Architecture and Building Research Institute, Ministry of Interior Affair, ROC. (in Chinese)

Loh, C. H., Z. K. Lee, T. C. Wu, and S. Y. Peng 2000: Ground motion characteristics of the Chi-Chi earthquake of 21 September 1999. Earthq. Eng. Struct. Dyn., 29, 867-897.

Ma, K. F., C. T. Lee, and Y. B. Tsai, T. C. Shin, and J. Mori, 1999: The Chi-Chi, Taiwan earthquake: Large surface displacements on an inland thrust fault. Eos, Trans., $A G U, \mathbf{8 0}, 605$, doi: 10.1029/99EO00405. [Link]

NRC (United States Nuclear Regulatory Commission), 1988: Probabilistic Seismic Hazard Analysis. National Academic Press, Washington, DC, 97 pp.

Petersen, M. D., A. D. Frankel, S. C. Harmsen, C. S. Mueller, K. M. Haller, R. L. Wheeler, R. L. Wesson, Y. Zeng, O. S. Boyd, D. M. Perkins, N. Luco, E. H. Field, C. J. Wills, and K. S. Rukstales, 2008: Documentation for the 2008 update of the United States national seismic hazard maps. Open-File Report 2008-1128, US Geological Survey, $61 \mathrm{pp}$.

Schwartz, D. P. and K. J. Coppersmith, 1984: Fault behavior and characteristic earthquakes: Example from the Wasatch and San Andreas fault zones. J. Geophys. Res., 89, 5681-5698, doi: 10.1029/JB089iB07p05681. [Link]

Teng, L. S. and C. T. Lee, 1996: Geomechanical appraisal 
of seismogenic faults in northeast Taiwan. J. Geol. Soc. China, 39, 125-142.

Tsai, C. C., L. H. Loh, and Y. T. Yeh, 1987: Analysis of earthquake risk in Taiwan based on seismotectonic zones. Mem. Geol. Soc. China, 9, 413-446.

Tsai, Y. B., 1985: A study of disastrous earthquakes in Taiwan, 1683-1895. Bull. Inst. Earth Sci., Acad. Sin., 5, $1-44$.

Tsai, Y. B., 1986: Seismotectonics of Taiwan. Tectonophysics, 125, 17-37, doi: 10.1016/0040-1951(86)90005-3. [Link]

Tsai, Y. B. and K. P. Chen, 1999: Seismicity studies in Taiwan as related to HAZ-Taiwan. Proceedings of the 1999 Workshop on Disaster Prevention/Management and Green Technology, Foster City, California, 1-19.

Tsai, Y. B. and M. W. Huang, 2000: Strong ground motion characteristics of the Chi-Chi, Taiwan earthquake of September 21, 1999. Earthq. Eng. Eng. Seism., 2, $1-21$.

Wang, C. Y. and C. T Sun, 1999: Interpretation of seismic stratigraphy in the Taipei basin. Special Issue for the Subsurface Geology and Engineering Environment of Taipei Basin, Special Publication of Central Geological Survey, 11, 273-292, Taipei, Taiwan, ROC.

Wang, C. Y., G. P. Chen, and D. T. Jong, 1994: The detection of active faults on Taiwan using shallow reflection seismics. Terr. Atmos. Ocean. Sci., 5, 277-293.

Wells, D. L. and K. J. Coppersmith, 1994: New empirical relationships among magnitude, rupture length, rupture area, and surface displacement. Bull. Seismol. Soc. Am., 84, 974-1002.
Wesnousky, S. G., 1994: The Gutenberg-Richter or characteristic earthquake distribution, Which is it? Bull. Seismol. Soc. Am., 84, 1940-1959.

Wu, F. T., 1978: Recent tectonics of Taiwan. J. Phys. Earth, 26, 265-299.

Wu, Y. M., T. C. Shin, and C. H. Chang, 2001: Near real-time mapping of peak ground acceleration and peak ground velocity following a strong earthquake. Bull. Seismol. Soc. Am., 91, 1218-1228, doi: 10.1785/0120000734. [Link]

Youngs, R. R. and K. J. Coppersmith, 1985: Implications of fault slip rates and earthquake recurrence models to probabilistic seismic hazard estimates. Bull. Seismol. Soc. Am., 75, 939-964.

Youngs, R. R., F. H. Swan, M. S. Power, D. P. Schwartz, and R. K. Green, 1987: Probabilistic analysis of earthquake ground shaking hazard along the Wasatch Front. Utah: Assessment of Regional Earthquake Hazards and Risk along the Wasatch Front. Utah. US Geological Survey Open File Report, 87-585, II, M-1-110.

Youngs, R. R., S. J. Chiou, W. J. Silva, and J. R. Humphrey, 1997: Strong ground motion attenuation relationships for subduction zone earthquakes. Seismol. Res. Lett., 68, 1, 58-73.

Yu, S. B. and H. Y. Chen, 1998: Strain accumulation in southwestern Taiwan. Terr. Atmos. Ocean. Sci., 9, 3150.

Yu, S. B., H. Y. Chen, and L. C. Kuo, 1997: Velocity field of GPS stations in the Taiwan area. Tectonophysics, 274, 41-59, doi: 10.1016/S0040-1951(96)00297-1. [Link] 